\title{
Dietary Strategies and Novel Pharmaceutical Approaches Targeting Serum ApoA-I Metabolism: A Systematic Overview
}

\author{
Lotte Smolders, Jogchum Plat, and Ronald P. Mensink \\ Department of Human Biology and Movement Sciences, School of Nutrition and Translational Research in Metabolism (NUTRIM), \\ Maastricht University Medical Center, P.O. Box 616, 6200 MD Maastricht, Netherlands
}

Correspondence should be addressed to Ronald P. Mensink; r.mensink@maastrichtuniversity.nl

Received 22 February 2017; Accepted 16 April 2017; Published 12 June 2017

Academic Editor: Michael B. Zemel

Copyright (c) 2017 Lotte Smolders et al. This is an open access article distributed under the Creative Commons Attribution License, which permits unrestricted use, distribution, and reproduction in any medium, provided the original work is properly cited.

\begin{abstract}
The incidence of CHD is still increasing, which underscores the need for new preventive and therapeutic approaches to decrease CHD risk. In this respect, increasing apoA-I concentrations may be a promising approach, especially through increasing apoA-I synthesis. This review first provides insight into current knowledge on apoA-I production, clearance, and degradation, followed by a systematic review of dietary and novel pharmacological approaches to target apoA-I metabolism. For this, a systematic search was performed to identify randomized controlled intervention studies that examined effects of whole foods and (non)nutrients on apoA-I metabolism. In addition, novel pharmacological approaches were searched for, which were specifically developed to target apoA-I metabolism. We conclude that both dietary components and pharmacological approaches can be used to increase apoA-I concentrations or functionality. For the dietary components in particular, more knowledge about the underlying mechanisms is necessary, as increasing apoA-I per se does not necessarily translate into a reduced CHD risk.
\end{abstract}

\section{Introduction}

The global incidence of coronary heart diseases (CHD) is still increasing, which underscores the need for novel and alternative approaches to prevent the initiation and progression of this disease already at an early stage. Since elevated serum low-density lipoprotein cholesterol (LDL-C) concentrations are causally related to $\mathrm{CHD}$, most dietary life style interventions and pharmaceutical treatments to prevent CHD so far are focused on lowering serum LDL-C concentrations. Despite successful intervention possibilities, there is still a substantial residual cardiovascular risk. Therefore, a possibility of further lowering CHD risk is to target multiple metabolic pathways simultaneously $[1,2]$. For example, statin treatment, to lower serum LDL-C concentrations, can be combined with other pharmaceutical agents, such as proprotein convertase subtilisin/kexin type 9 inhibitors, which substantially further lower serum LDL-C concentrations [3]. Also, the Niemann-Pick Like Intracellular Cholesterol Transporter 1 inhibitor ezetimibe can be used, which has been shown to further lower the number of myocardial infarctions with $13 \%$, strokes with $14 \%$, and ischemic strokes with $21 \%$ [4]. Besides combined interventions to further increase the LDL-C lowering potential, it can be considered to target at the same time other CHD risk parameters including serum high density lipoprotein (HDL) cholesterol (HDL-C), apolipoprotein A-I (apoA-I), triacylglycerol or lipoprotein(a) concentrations, and/or blood pressure [5]. These parameters may be interrelated. An inverse relationship exists, for example, between serum triacylglycerol and HDL-C concentrations. Thus, interventions that change triacylglycerol may therefore also affect HDL metabolism [6]. In this review we will however focus on possibilities to further reduce CHD risk via novel and alternative dietary and pharmacological interventions targeting apoA-I metabolism.

1.1. Increasing HDL Functionality by Increasing ApoA-I. So far, interventions specifically targeting to increase serum HDL-C concentrations did not report any protective cardiovascular effect, which has clearly negatively influenced the interest to develop novel interventions to elevate serum HDLC. However, recent evidence suggests that the focus should be on optimizing HDL functionality instead of elevating circulating serum HDL-C concentrations [7]. By increasing 
their functionality, HDL particles are able to take up more cholesterol from peripheral tissues, that is, the so-called cholesterol efflux. In addition, a more functional HDL particle will be more antioxidative - in particular by inhibiting LDL oxidation-and more antithrombotic and will have a higher anti-inflammatory and antiapoptotic activity [8]. A wealth of evidence from epidemiological, in vitro, and in vivo studies suggests that higher apoA-I concentrations protect against CHD development [9]. By increasing apoAI concentrations, the resulting newly produced small HDL particles (i.e., prebeta HDL) will be highly functional, thereby enhancing cholesterol efflux [8]. Indeed, it has been found that apoA-I concentration is the strongest predictor for cholesterol efflux capacity [10]. ApoA-I is the major protein of HDL particles [11] contributing to approximately $33 \%$ of the total HDL particle mass and up to $60 \%$ of the HDL protein mass [12]. The most likely mechanism explaining the beneficial effects of elevated serum apoA-I concentrations origins from the fact that apoA-I is the ligand for ATPbinding cassette transporter A1 (ABCA1), as such mediating cholesterol efflux from lipid-laden macrophages [8]. Based on this information, Smits et al. wrote a clear plead for strategies to increase serum apoA-I concentrations as the most promising target for enhancing HDL functionality, thereby decreasing cardiovascular disease (CVD) risk [13]. However, lowering $\mathrm{CHD}$ risk by increasing endogenous apoA-I production, by decreasing apoA-I degradation, or by providing exogenous apoA-I has for unknown reasons not yet been investigated into great detail. Therefore, the question remains whether specifically targeting apoA-I metabolism is a suitable target to reduce CHD risk.

In this review we will first briefly provide insight into the current knowledge of apoA-I synthesis, clearance, and degradation, followed by a detailed overview of dietary and novel experimental pharmaceutical developments targeting circulating apoA-I concentrations.

\section{ApoA-I}

2.1. ApoA-I Synthesis. ApoA-I mRNA is expressed in cells of the liver and small intestine [14], where it is translated into a pre-pro-apoA-I protein. The presegment needs cotranslational cleavage [15], which takes place during translocation of the protein into the endoplasmatic reticulum by a signal peptidase $[16,17]$. This results in a stable intracellular, pro-apoA-I protein [15], which is secreted into blood and lymph. Directly after secretion of pro-apoA-I, the proprotein is cleaved of by Bone Morphogenetic Protein-1 (BMP-1) and Procollagen C-proteinase Enhancer-2 Protein (PCPE2) (Figure 1) [18, 19]. It is evident that the cleavage of the prosegment is essential for the secretion of newly formed intracellular apoA-I. Deletion of the coding sequence of the prosegment causes accumulation of apoA-I in the cell [20], decreases the efficiency of apoA-I mRNA expression [17], and impairs the secretion of apoA-I into blood and lymph $[17,20]$. The cleavage of the proprotein occurs relatively rapid, while the residence time for pro-apoA-I in plasma is only 5.5 hours, in contrast to the residence time for mature apoA-I of 6.5 days [21]. About $4-8 \%$ of the circulating
apoA-I pool is pro-apoA-I $[15,22,23]$. After cleavage of the prosegment, apoA-I accepts cholesterol and phospholipids from ABCA1 [24] to form a pre- $\beta$ HDL particle (Figure 1). In other words, apoA-I is the starting point for the synthesis of a functional HDL particle and therefore essential for the formation and maturation of novel HDL particles [16]. In the circulation, lecithin-cholesterol acyltransferase esterifies the free cholesterol in these pre- $\beta$ HDL particles, thereby forming $\mathrm{HDL}_{3}$ and finally $\mathrm{HDL}_{2}$ [25]. The ATP-binding cassette G1 transporter and scavenger receptor class B type 1 (SR-B1) contribute to the cholesterol efflux from peripheral tissues and macrophages to these mature HDL particles. After binding of $\mathrm{HDL}_{2}$ to SR-B1 on the liver, cholesterol esters are taken up and lipid-depleted apoA-I is returned to the circulation. These apoA-I-rich lipid-depleted HDL particles can again acquire cholesterol and phospholipids-forming an pre- $\beta$ HDL particle-or can be cleared from the circulation [26].

2.2. ApoA-I Clearance. Several organs are involved in apoAI clearance and degradation [26]. Calculations in rabbits have indicated that renal apoA-I clearance accounts for approximately $68-70 \%$ of total apoA-I catabolism. Also in humans, the kidney is the major site for apoA-I clearance $[26,27]$. In the kidneys, the uptake of HDL particles is limited, because the intact lipoprotein particles are too large to pass the glomerular filtration barrier. However, newly formed or recycled lipid free apoA-I can pass this barrier. In the proximal tubule of the glomerulus, apoA-I binds the receptors cubilin and megalin [28], which mediate endocytosis and delivery of the protein to the lysosomes [29, 30], resulting in complete degradation of the apoA-I protein. The amino acids can be reused for de novo protein synthesis [31]. While the kidney plays a major role in apoA-I degradation, the liver accounts for $26 \%$ of the apoA-I clearance, at least in rats. It is not known how the hepatocytes take up the apoAI particles, but the apoA-I catabolic products are excreted from the liver via the bile into the gut. In the gut, they are further digested and absorbed or excreted from the body. Other tissues, besides kidney and liver, which are to a lesser extent involved in the degradation of apoA-I, are ovaries, adrenals, and spleen, which secrete apoA-I catabolic products into the urine (Figure 1) [26].

Increasing apoA-I concentrations via reducing apoA-I clearance is for unknown reasons not a subject of investigation. Consequently, it is also not known whether inhibiting apoA-I clearance affects HDL functionality. Therefore, decreasing apoA-I clearance is currently not a target for interventions, whereas elevating de novo apoA-I production certainly is [32].

\section{Dietary Interventions Affecting ApoA-I Metabolism}

It has been clearly shown that dietary components can change serum apoA-I concentrations. We here provide an overview of randomized controlled dietary intervention studies that have examined the effects of whole foods and (non)nutrients on apoA-I concentrations or apoA-I 


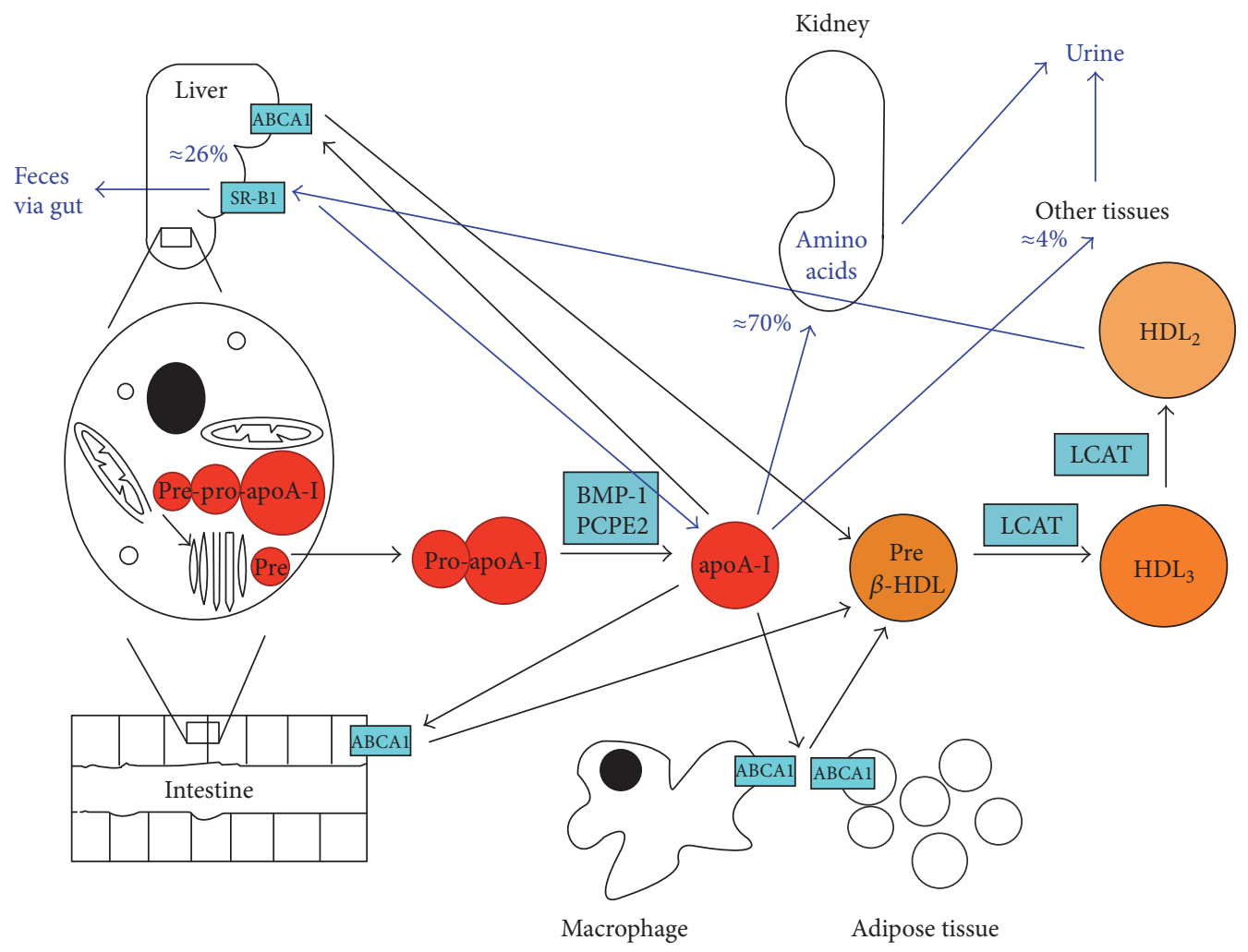

FIGURE 1: Simplified scheme of the synthesis, metabolism, and clearance of apoA-I. ApoA-I is synthesized in cells of the liver and intestine as pre-pro-apoA-I. After translocation to the endoplasmic reticulum, the preprotein is cleaved of and pro-apoA-I is secreted into blood and lymph. In the circulation, the prosegment is directly cleaved of by Bone Morphogenetic Protein-1 (BMP-1) and Procollagen C-proteinase Enhancer-2 Protein (PCPE2). After this, apoA-I accepts cholesterol and phospholipids from ABCA1, forming a pre- $\beta$ HDL particle. In the circulation, lecithin-cholesterol acyltransferase esterifies (LCAT) the free cholesterol in these pre- $\beta$ HDL particles, forming HDL $\mathrm{H}_{3}$ and finally $\mathrm{HDL}_{2}$, as indicated by the black arrows. After binding of $\mathrm{HDL}_{2}$ to SR-B1 on the liver, the cholesterol esters are taken up and lipid-depleted apoA-I is returned to the circulation. These apoA-I-rich particles can again acquire cholesterol and phospholipids or can be cleared from the circulation. Clearance will take place for $70 \%$ by the kidney, where apoA-I is broken down into amino acids and ultimately excreted in the urine. $26 \%$ of the free apoA-I will be cleared by the liver, and apoA-I catabolic products will then be excreted via biliary secretion into the gut and further digested and absorbed or excreted from the body through the feces. $4 \%$ of the free apoA-I will go to other tissues and finally will end up in the urine, as indicated by the blue arrows.

metabolism. Only crossover and parallel studies were included. Potentially relevant studies published before January 2017 were identified by a systematic search of the database PubMed (https://www.ncbi.nlm.nih.gov). The following search terms were used to search in titles and abstracts: ((Clinical Trial[Publication Type]) OR randomized controlled trial[Publication Type])) AND apolipoprotein $\mathrm{A}^{*}[\mathrm{MeSH}$ Terms]. The selection was performed in two steps. First, titles and abstracts were screened. Studies were selected if they met the following inclusion criteria: human intervention study with adults, dietary intervention study, and measurement of apoA-I concentrations. In the second step, full-texts of the selected articles were read to extract fasting or postprandial apoA-I values. Then, a search was performed to find meta-analysis of each food or (non)nutrient group. When a meta-analysis was found, it is included in this review together with the articles identified by us, which were not part of the meta-analysis. Changes in apoA-I concentrations were expressed as percentages, if possible. When percentages were not reported, they were calculated from the mean values as reported in the articles. Furthermore, the list of articles was screened for studies that investigated the effects on cholesterol efflux, apoA-I production rate $(\mathrm{PR})$, or fractional catabolic rate (FCR).

3.1. Alcohol. Based on a meta-analysis including 16 studies with in total 374 subjects, Brien et al. concluded that alcohol consumption (women: $>15 \mathrm{~g}$ alcohol/day; men: $>30 \mathrm{~g}$ alcohol/day) increased fasting plasma apoA-I concentrations with $10.1 \mathrm{mg} / \mathrm{dL}$ (95\% CI 7.3-12.9 mg/dL) [33]. A later study, not included in this meta-analysis, also showed a higher fasting apoA-I concentration after alcohol consumption as compared with no alcohol consumption [34]. Moreover, postprandial apoA-I concentrations also increased after alcohol consumption [35]. These effects did not depend on the source (red wine, beer, and Dutch gin) of alcohol [36]. Lavy et al. however reported that red wine increased apoA-I as compared with white wine consumption [37]. Also, Gepner et al. observed that red wine increased apoA-I concentrations as compared with water consumption, but white wine did not significantly 
change apoA-I concentrations as compared with water or red wine [38]. Furthermore, alcohol consumption not only elevated circulating apoA-I concentrations but also improved HDL functionality as shown by an increased cholesterol efflux capacity $[36,39,40]$. In one study, the kinetics of apoA-I have been examined. It was reported that apoA-I PR increased and apoA-I FCR decreased after alcohol consumption (Table 1) [41].

3.2. Boiled and Filtered Coffee, Caffeine, and Tea. In six studies, the effects of boiled or filtered coffee, caffeine, and tea on fasting apoA-I concentrations have been compared. In none of the studies, significant differences in apoA-I concentrations were observed (Table 2) [42-47].

3.3. Fatty Acids. In a recent meta-analysis including 104 diets from forty-two well-controlled intervention studies the effects of the various fatty acids on fasting serum apoA-I concentrations were estimated. Effects of fish-fatty acids were not included in that meta-analysis and will be discussed in the next paragraph. A significant increase in serum apoA-I concentrations was found when 1 energy $\%$ of carbohydrates was replaced by saturated fatty acids (SFA; $8.4 \mathrm{mg} / \mathrm{dL}, 95 \%$ CI 6.4-10.5), cis-monounsaturated fatty acids (cis-MUFA; $5.5 \mathrm{mg} / \mathrm{dL}, 95 \%$ CI 3.7-7.3), and cis-polyunsaturated fatty acids (cis-PUFA; $2.3 \mathrm{mg} / \mathrm{dL}, 95 \%$ CI 0.1-4.6). cis-MUFA mainly referred to oleic acid and cis-PUFA to linoleic acid plus some $\alpha$-linolenic acid. This meta-analysis further showed that fasting apoA-I concentrations were significantly increased by replacement of 1 energy\% from carbohydrates with lauric acid (C12:0; $19.2 \mathrm{mg} / \mathrm{dL}, 95 \%$ CI 14.6-12.7), myristic acid (C14:0; $8.8 \mathrm{mg} / \mathrm{dL}, 95 \%$ CI 0.5-13.1), and palmitic acid (C16:0; $6.5 \mathrm{mg} / \mathrm{dL}, 95 \%$ CI 3.8-9.3), while replacement with stearic acid (C18:0) did not change apoA-I concentrations [48]. For these latter analyses, 88 diets from 34 studies were included. In another meta-analysis based on 17 diets from 10 studies, Brouwer (2016) described the effects of trans-fatty acids (TFA) on circulating fasting apoA-I concentrations. It was reported that replacement of 1 energy\% of carbohydrates for total TFA increased apoA-I concentrations $(3.3 \mathrm{mg} / \mathrm{dL}$, 95\% CI 4.7-1.9). When a difference was made between industrial and ruminant TFA, it was found that replacement with industrial TFA significantly increased fasting apoA-I concentrations $(3.3 \mathrm{mg} / \mathrm{dL}, 95 \%$ CI 4.8-1.8), while ruminant TFA did not $(4.6 \mathrm{mg} / \mathrm{dL}, 95 \% \mathrm{CI}:-22.0-12.9)$. This may be due to a lack of power, since only two studies investigated ruminant TFA. Furthermore, this meta-analysis also showed that replacement of 1 energy\% from TFA with SFA increased fasting apoA-I concentrations $(2.6 \mathrm{mg} / \mathrm{dL}, 95 \% \mathrm{CI} 1.4-3.9)$, while replacement with MUFA did not change apoA-I concentrations and replacement with cis-PUFA decreased fasting apoA-I concentrations $(-1.7 \mathrm{mg} / \mathrm{dL}, 95 \% \mathrm{CI}-2.8--0.6)$ (Table 3) [49].

Several studies have examined the effects of the various fatty acids on serum apoA-I metabolism. A TFA diet increased apoA-I FCR as compared with SFA, but the FCR after cis-PUFA consumption did not differ from the TFA or SFA diets. ApoA-I PR was not different between the various diets [52]. Moreover, a cis-PUFA diet did not affect
apoA-I FCR [50] and both FCR and PR decreased after low fat consumption compared with high cis-MUFA consumption [51]. In contrast, Labonté et al. have reported that replacing 13 energy $\%$ of carbohydrates with cis-MUFA decreased apoA-I FCR with no change in apoA-I PR (Table 3) [53]. The different results between these two studies $[51,53]$ may have been due to the significant weight loss in the study of Desroches et al., which may have confounded to some extent the effect of MUFA on apoA-I kinetics.

3.4. Fish and Fish-Fatty Acids. Most studies investigating the effects of omega-3 fatty acids from fatty fish, mainly eicosapentaenoic acid (EPA) and docosahexaenoic acid (DHA), did not observe any differences in fasting and postprandial apoA-I concentrations [54, 55, 57-66, 68-71, 73-79]. However, in two studies, all in healthy men, fasting apoAI concentrations decreased after fish oil supplementation. The first study showed lower apoA-I concentrations after pollock oil (rich in EPA) and salmon oil (rich in DHA), but not after tuna oil (rich in DHA) consumption as compared with butter [56]. The second study found lower apoA-I concentrations after EPA oil supplementation compared with DHA oil supplementation [67]. On the other hand, one study found an increase in fasting apoA-I concentrations after a diet high in fish-fatty acids compared with a diet low in fishfatty acids. In this study, the diets were matched for total fat (Table 4) [72].

Five studies have investigated the effects of fish on fasting apoA-I concentrations. In one study, fatty fish (salmon, rainbow trout, Baltic herring, whitefish, vendace, and tuna) consumption increased apoA-I concentrations compared with lean fish (pike, pike-perch, perch, saithe, and cod) consumption. However, it did not change apoA-I concentrations as compared with lean meat (beef and pork) consumption [83]. The other three studies did not find differences in apoA-I concentrations after fish consumption, of which two compared fatty fish with lean meat $[82,96]$ and one compared prawns with crab [84]. A limitation of the study of Lindqvist et al. is that participants consumed in total 35 energy $\%$ of fat in the herring period and only 10 energy $\%$ of fat in the meat period [82], which may have affected apoA-I concentrations. Comparisons between fish and meat consumption are probably not confounded by differences in the intake of the source of protein, as suggested by Gascon et al. In that study, the effects of proteins in lean fish (cod, sole, pollack, and haddock) were compared with those of animal protein (lean beef, pork, veal, eggs, skimmed milk, and milk products). No differences on fasting apoA-I concentrations were found (Table 4) [81].

3.5. Fibers. Studies comparing the effects of oat germ, low in fiber, with those of wheat germ, high in fiber, consumption did not find any differences in fasting apoA-I concentrations [80,85-89]. In four of these studies, it was explicitly reported that the macronutrient composition of the experimental diets was comparable $[80,85,86,88]$. Mekki et al. observed that a high-fiber diet did not change fasting apoA-I concentrations as compared with a low fiber diet [90]. On the other hand, decreased fasting apoA-I concentrations were found after 


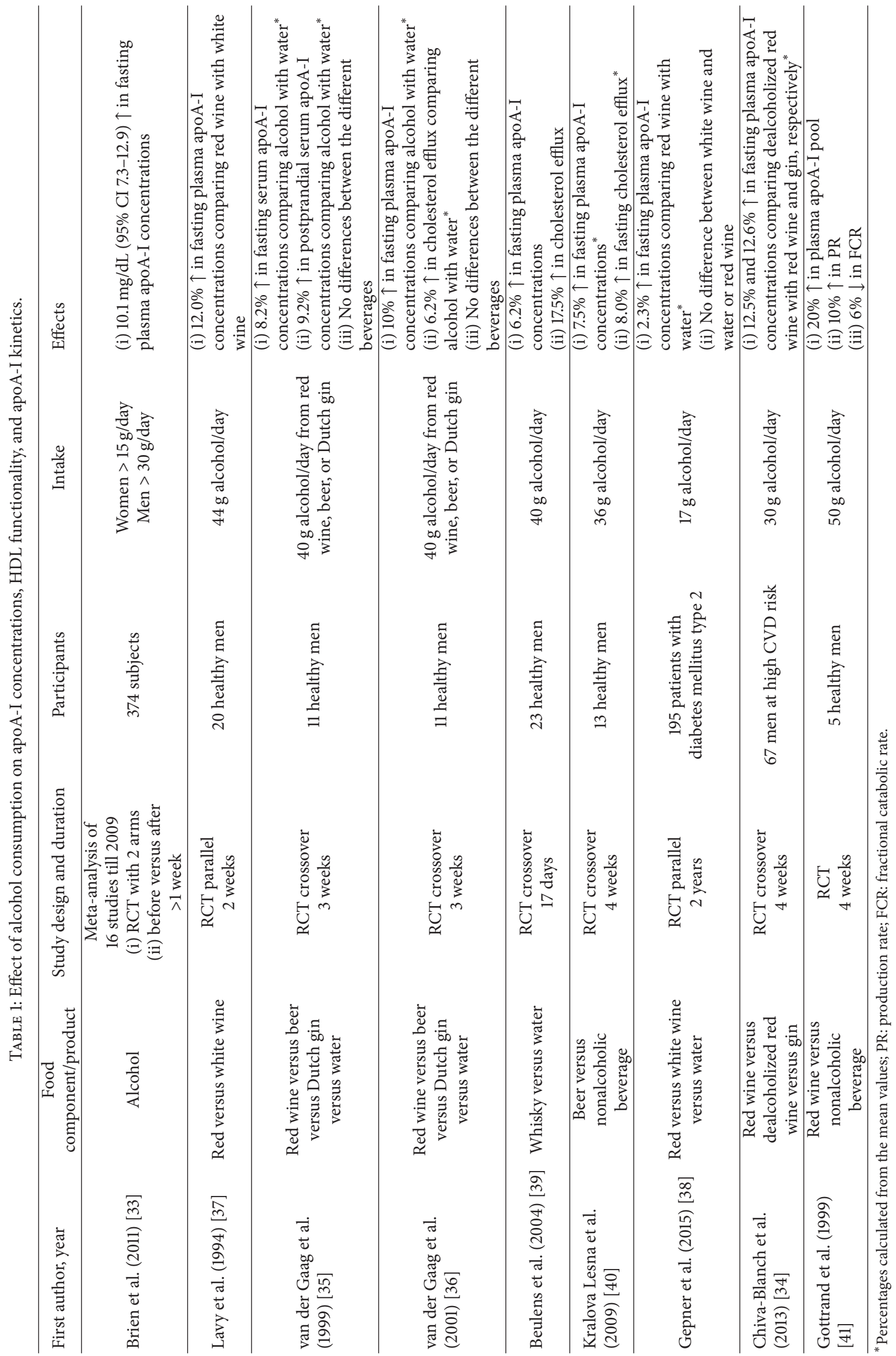




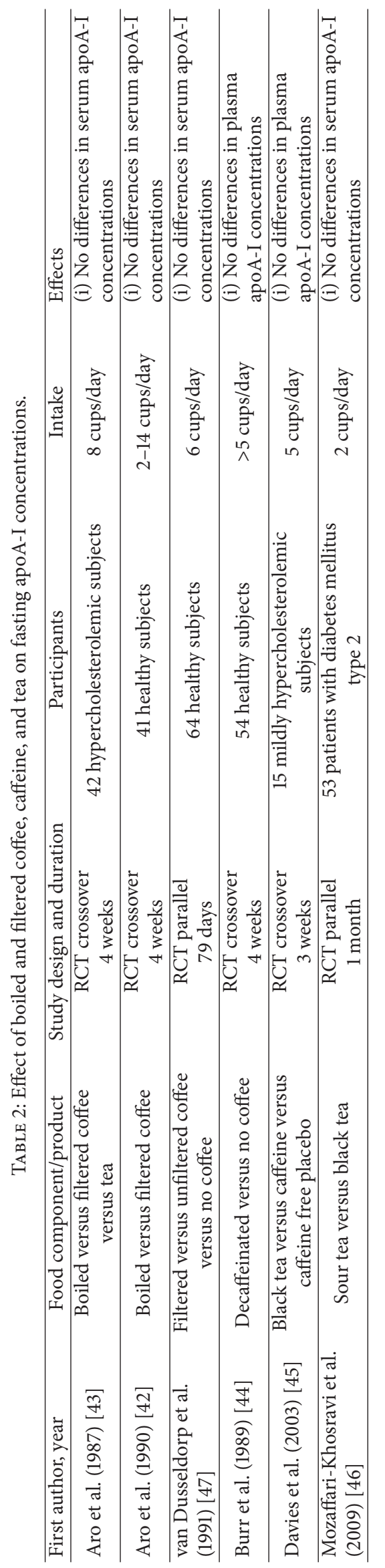




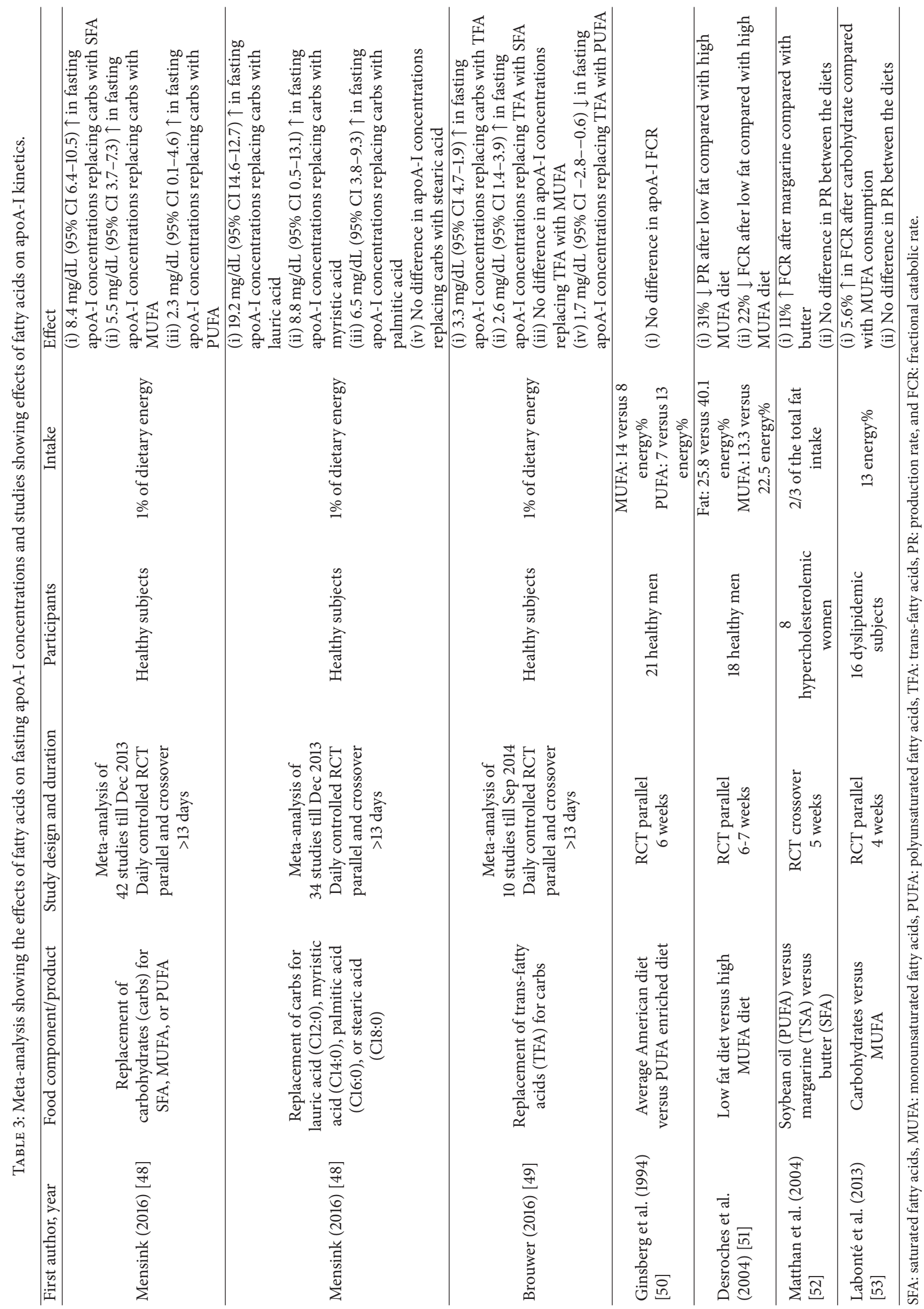




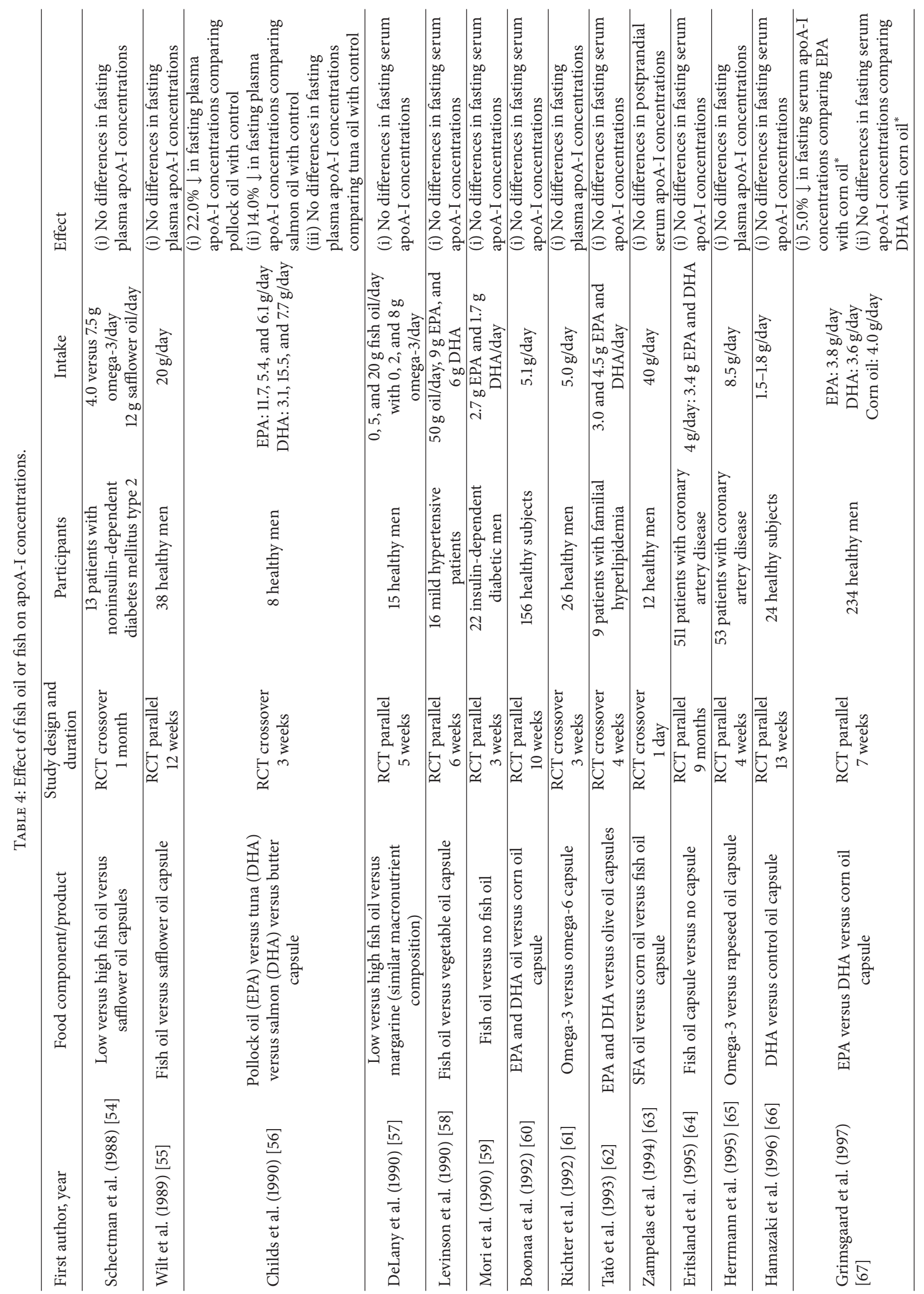




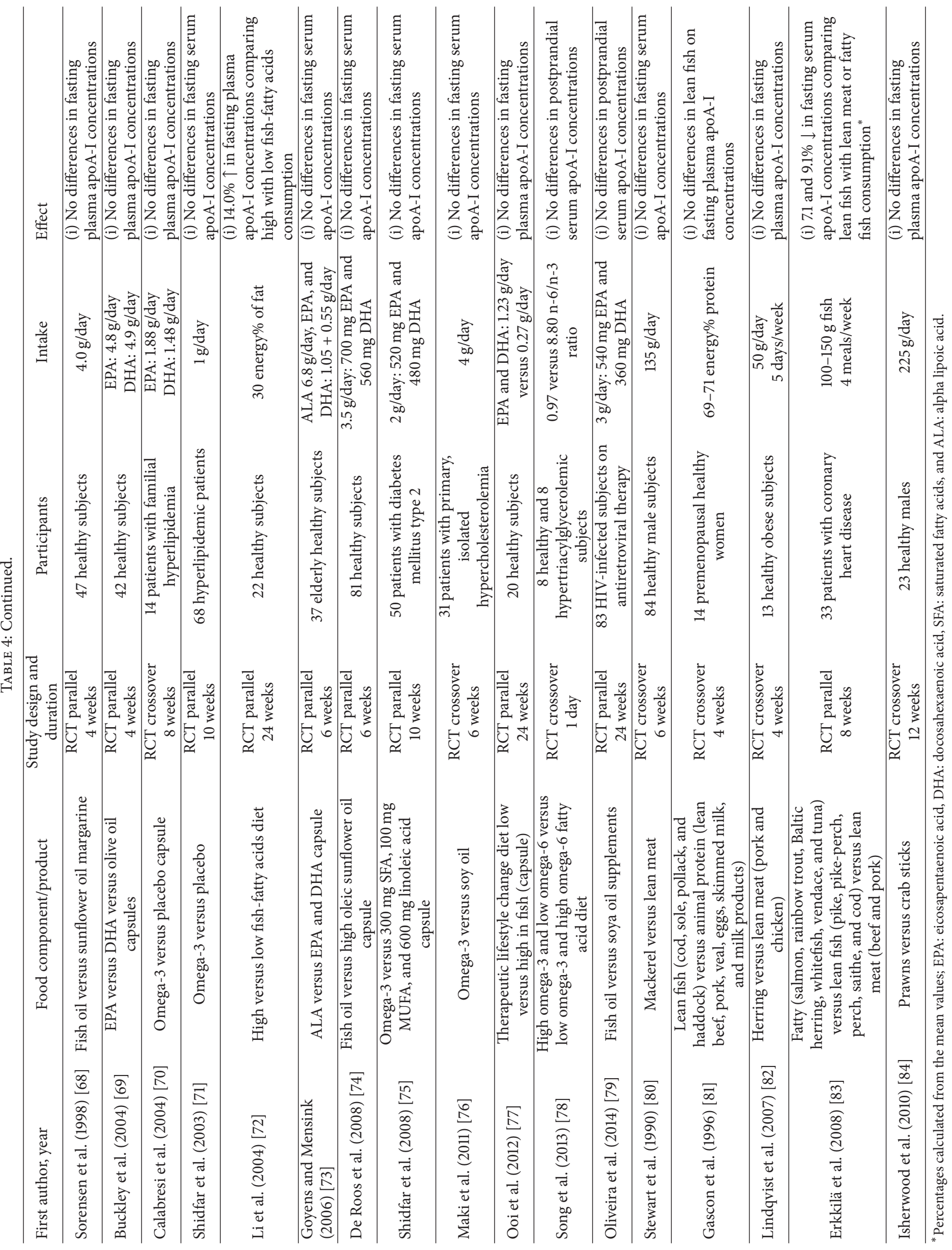


a high $\beta$-glucan and psyllium diet as compared with a low fat, low-cholesterol control diet [91]. The water-soluble fiber arabinoxylan also decreased fasting apoA-I concentrations as compared with the control diet, which had a similar macronutrient composition [92]. Furthermore, no differences in fasting apoA-I concentrations were observed between the soluble and insoluble forms of $P$. ovate [93]. The water-soluble fiber $\beta$-glucan did not affect fasting apoAI concentrations [94]. Furthermore, wheat germ consumption increased fasting apoA-I concentrations compared with flaxseed consumption (Table 5) [95].

3.6. Nuts. In one short-term study, walnut consumption significantly increased fasting serum apoA-I concentrations [97], but these effects were not found in two longer-term studies [98, 99]. Almond consumption did also not affect fasting apoA-I concentrations [100,101]. Likewise, hazelnuts $[102,103]$ and pistachio nuts did not change fasting apoA-I concentrations [104]. A limitation of some of the studies is that not all experimental diets were matched for differences in fat and fatty acid composition. In some of these studies, the diets containing nuts provided more energy from fat than the control diets [99-102]. Furthermore, the nut diets were sometimes also lower in SFA and higher in PUFA than the control diets $[99,101]$. Although these differences in nutrient intakes are inherent to consuming more nuts, it is not likely that the effects observed are due to minor component in nuts, since fatty acids increase apoA-I concentrations as compared with carbohydrates [48]. However, most other studies that used a control diet with similar fat and fatty acid composition did also not find any effects of the consumption of nuts on apoA-I concentrations (Table 6) $[98,103,104]$.

3.7. Plant Sterols and Stanols. Most studies examining the effects of plant sterols on serum lipids did not demonstrate an effect of plant sterols on fasting apoA-I concentrations [106, 107, 109-114]. In one study, comparing olive oil and olive oil with plant sterol esters and sunflower oil with plant sterol esters, fasting apoA-I concentrations increased when plant sterol esters were consumed together with olive oil, but apoA-I concentrations were comparable during the other two interventions [108]. Furthermore, one study showed an increase in fasting apoA-I concentrations comparing 3 months of prudent diet consumption (National Cholesterol Education Program) with added plant sterols, with prudent diet consumption alone [111]. One study examined the effects of plant stanols on fasting apoA-I concentrations and found increased apoA-I concentrations comparing 6 weeks of sitostanol consumption with no sitostanol consumption [105]. Finally, no changes in apoA-I PR and FCR were found after plant sterol or stanol consumption (Table 7) $[105,110]$.

3.8. Soy Proteins or Isoflavones Isolated from Soy. Studies investigating the effects of soy protein on fasting apoA-I concentrations showed inconsistent outcomes. Eight studies using different amounts of soy protein for 3 weeks till 3 months did not find changes in fasting apoA-I concentrations $[115,116,118-121,123-125]$. On the other hand, in one study products containing soy protein increased fasting apoA-I concentrations as compared with products containing casein [117], while in another study products with soy protein decreased fasting apoA-I as compared with products containing casein [122]. Furthermore, two studies found different effects of various soy products on fasting apoA-I concentrations $[126,127]$. Soy-milk increased apoA-I concentrations as compared with soy nuts and soy flour, but no differences were found as compared with animal protein [126]. Soy nut and soy protein consumption increased apoA-I concentrations as compared with the control group without soy [127]. Two studies have investigated the effects of isoflavones isolated from soy on apoA-I concentrations and showed no effect on fasting $[128,129]$ and postprandial apoA-I concentrations (Table 8) [129].

3.9. Others. Many other products and food components have been studied for their effects on apoA-I concentrations. In most of these studies, which included eggs [130], dried garlic [131, 134], beta-carotene [132], phytochemicals with cytochrome P-450-inducing activity [133], magnesium [135], eggplant [136], dry beans [137], kiwifruits [138], and polyphenols [139], no effects on fasting apoA-I concentrations were observed. In addition, sphingolipids did not change postprandial apoA-I concentrations [140]. On the other hand, red grape juice [141], a mixture of citrus flavonoids and tocotrienols [142], vitamin D supplementation [143, 144], vitamin D plus calcium supplementation [144], theobromine [145], orange juice [146], and a high dose of grape pomace and omija fruit [147] all increased fasting apoA-I concentrations (Table 9).

\section{Pharmacological Approaches Targeting ApoA-I Metabolism}

Although not always specifically developed for this purpose, several well-known drugs like statins $[7,167]$ and CETP inhibitors [168-171] affect serum apoA-I concentrations. However, since this review focuses on novel strategies to increase serum apoA-I concentrations, we here describe only approaches that are currently in development and are specifically designed to target a change in apoA-I metabolism. Potentially relevant studies published before January 2017 were identified by a systematic search of the database PubMed (https://www.ncbi.nlm.nih.gov). The following search terms were used to search in titles and abstracts: (Pharmacological AND approaches AND apoA-I). First, all abstracts were screened and the pharmacological approaches were divided into three categories: apoA-I mimetics, apoA-I infusions, and others. Second, a new search was performed with the search terms: (apoA-I mimetics AND apoA-I infusions AND RVX208 AND LCAT infusion AND clinical trial) to select all studies published before January 2017 that investigate apoA-I mimetics, apoA-I infusions, and RVX-208 in humans.

4.1. ApoA-I Mimetics. ApoA-I mimetics are small amphipathic peptides that resemble apoA-I in biological function and structure [172]. These mimetics are not the intact apoAI protein, but small fragments of the protein with certain biological functions. These small peptides can be given orally 


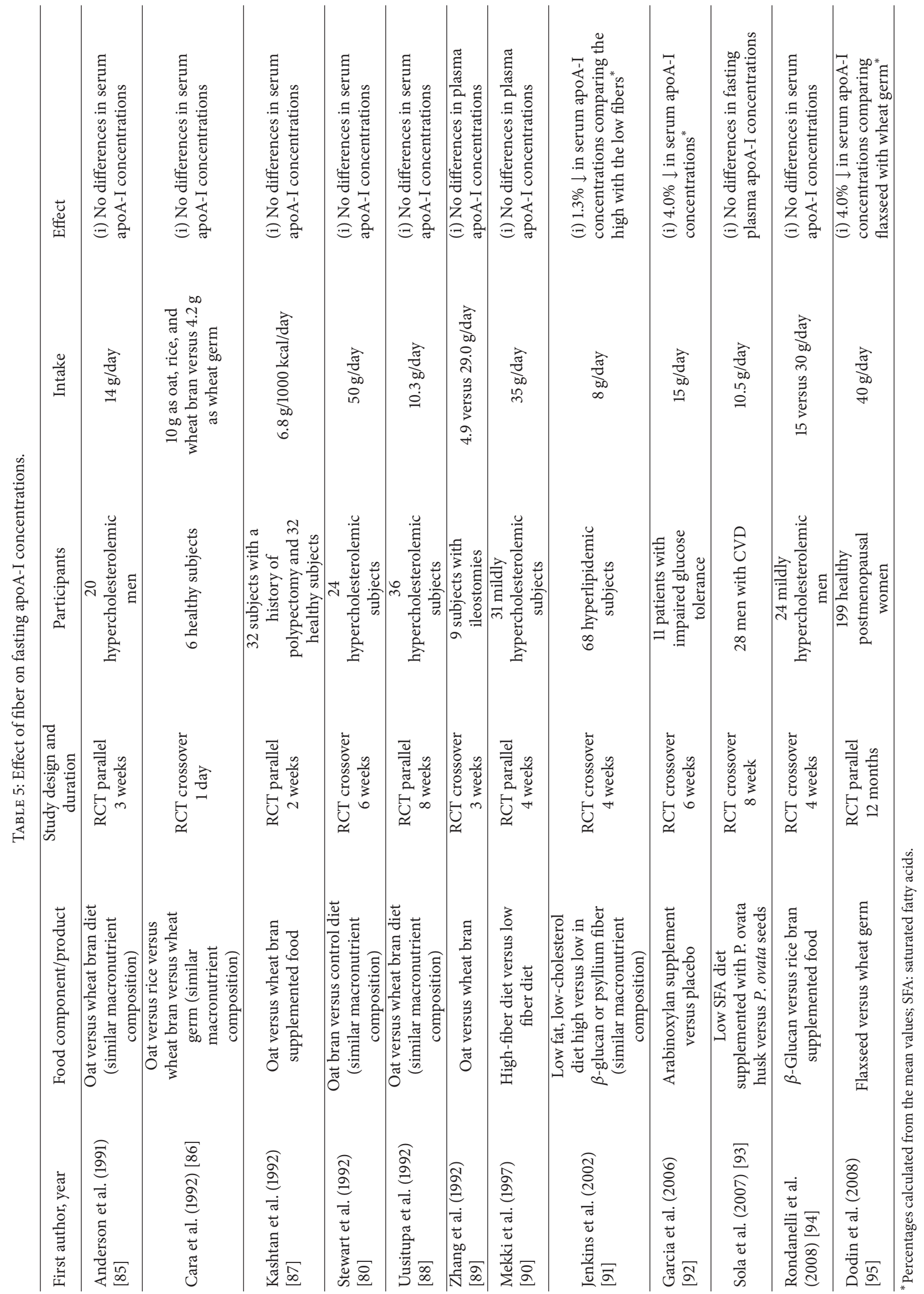




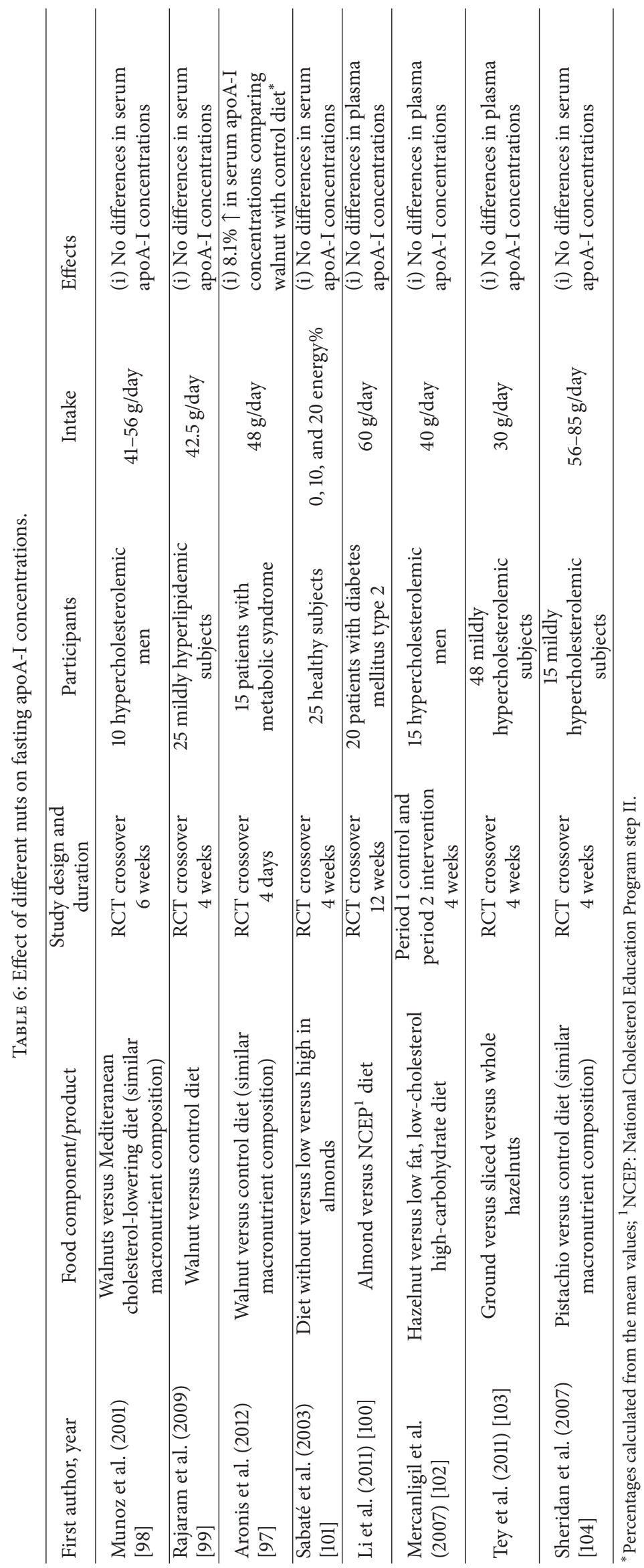




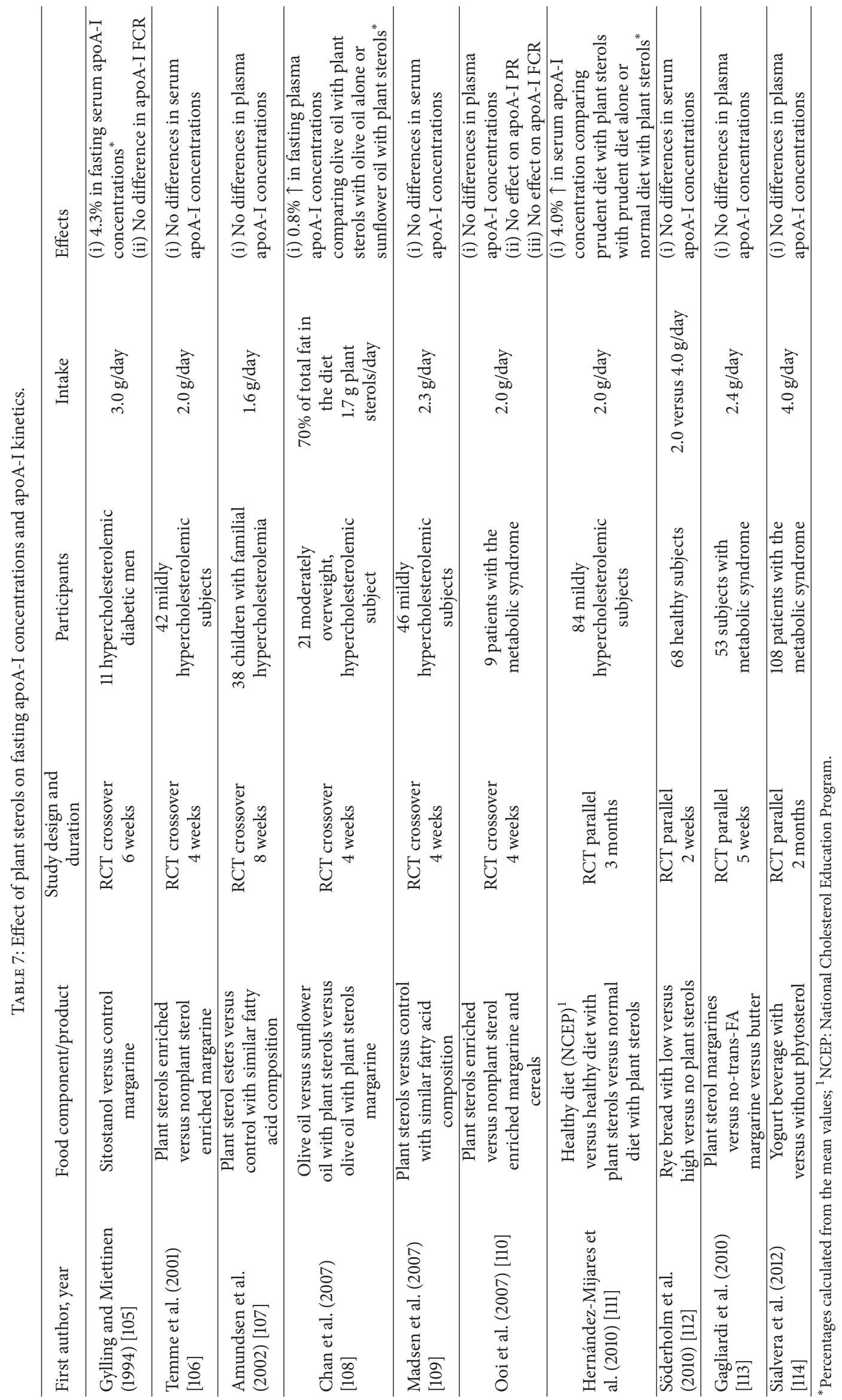




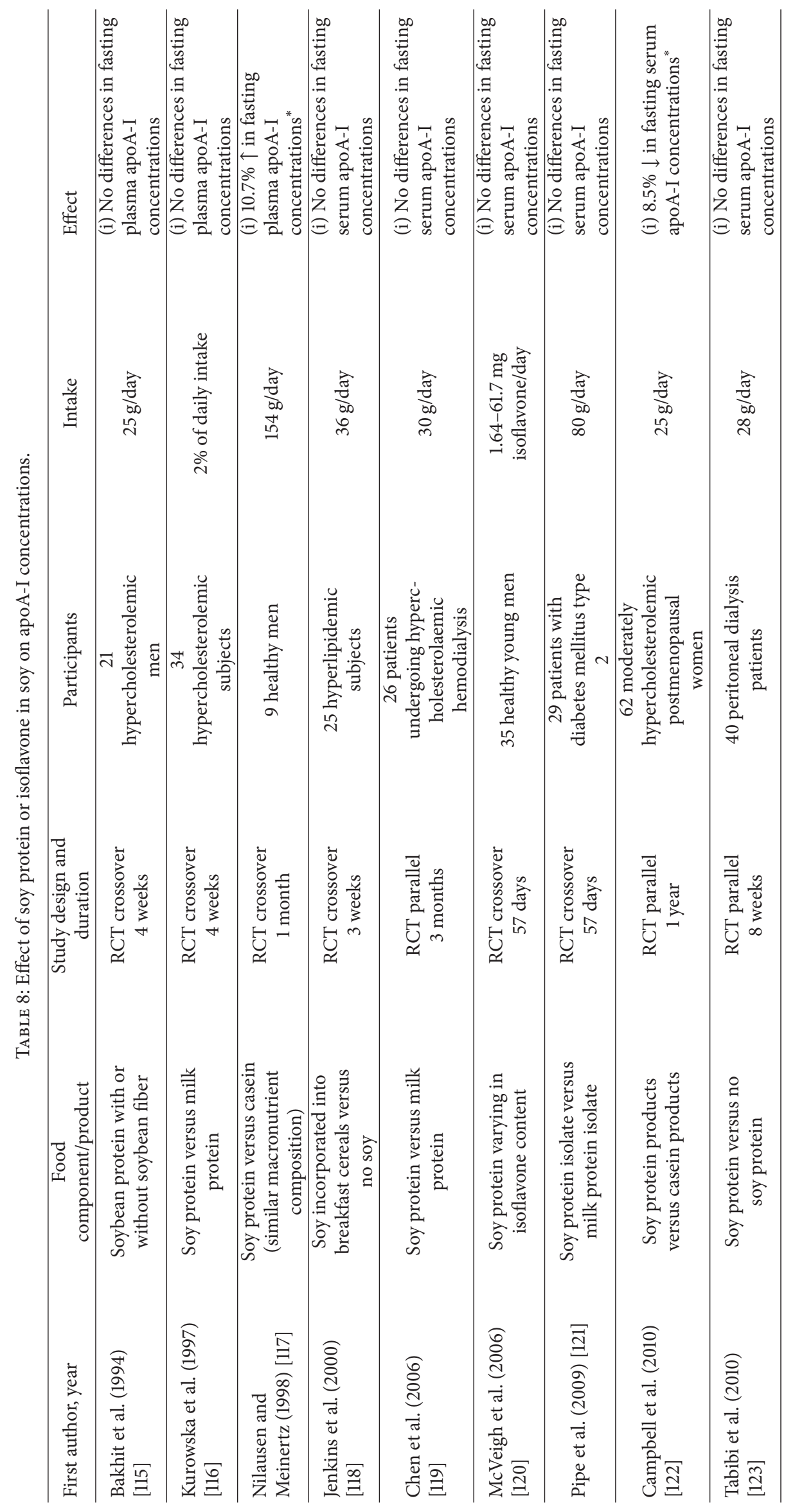




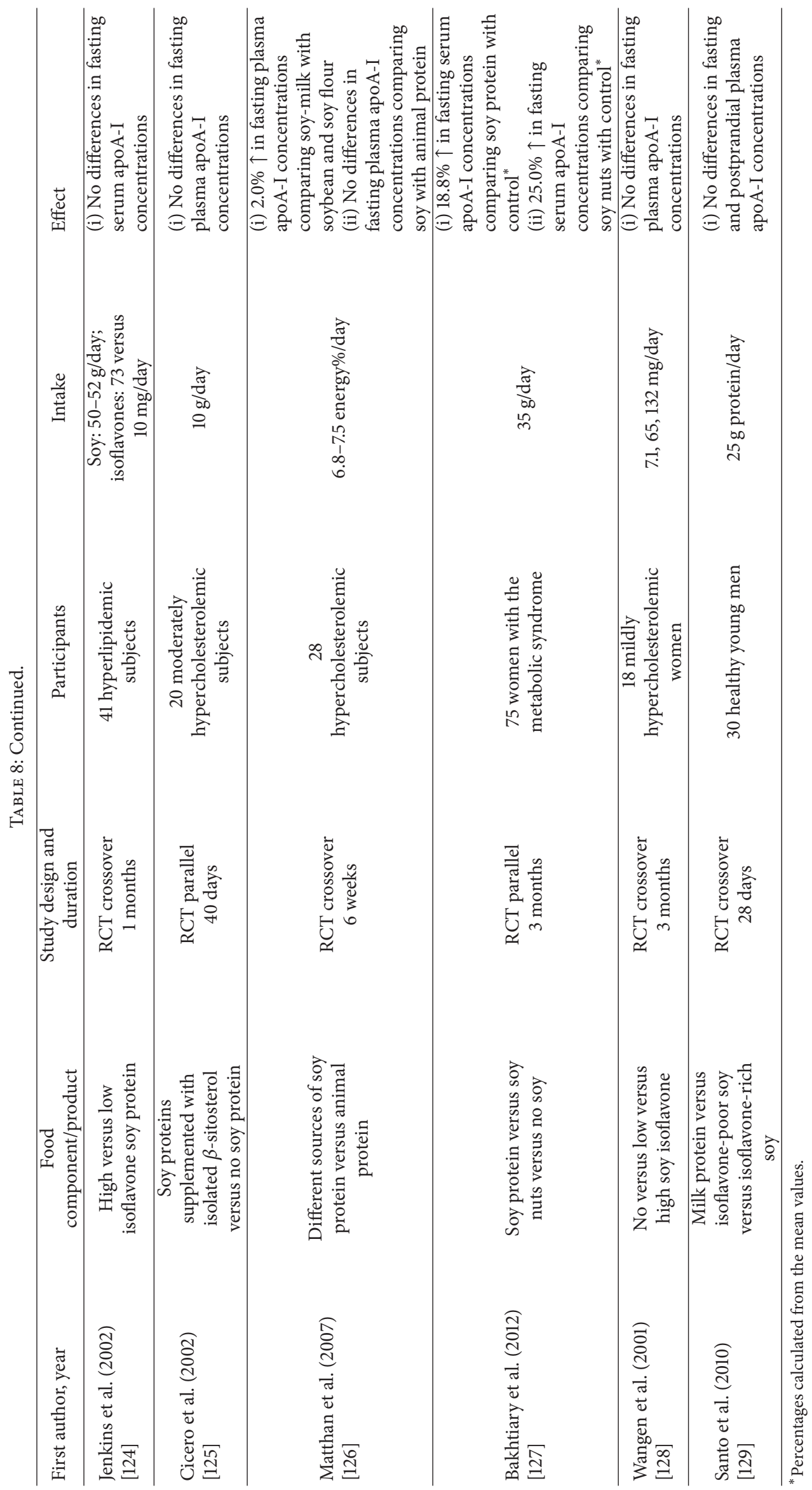




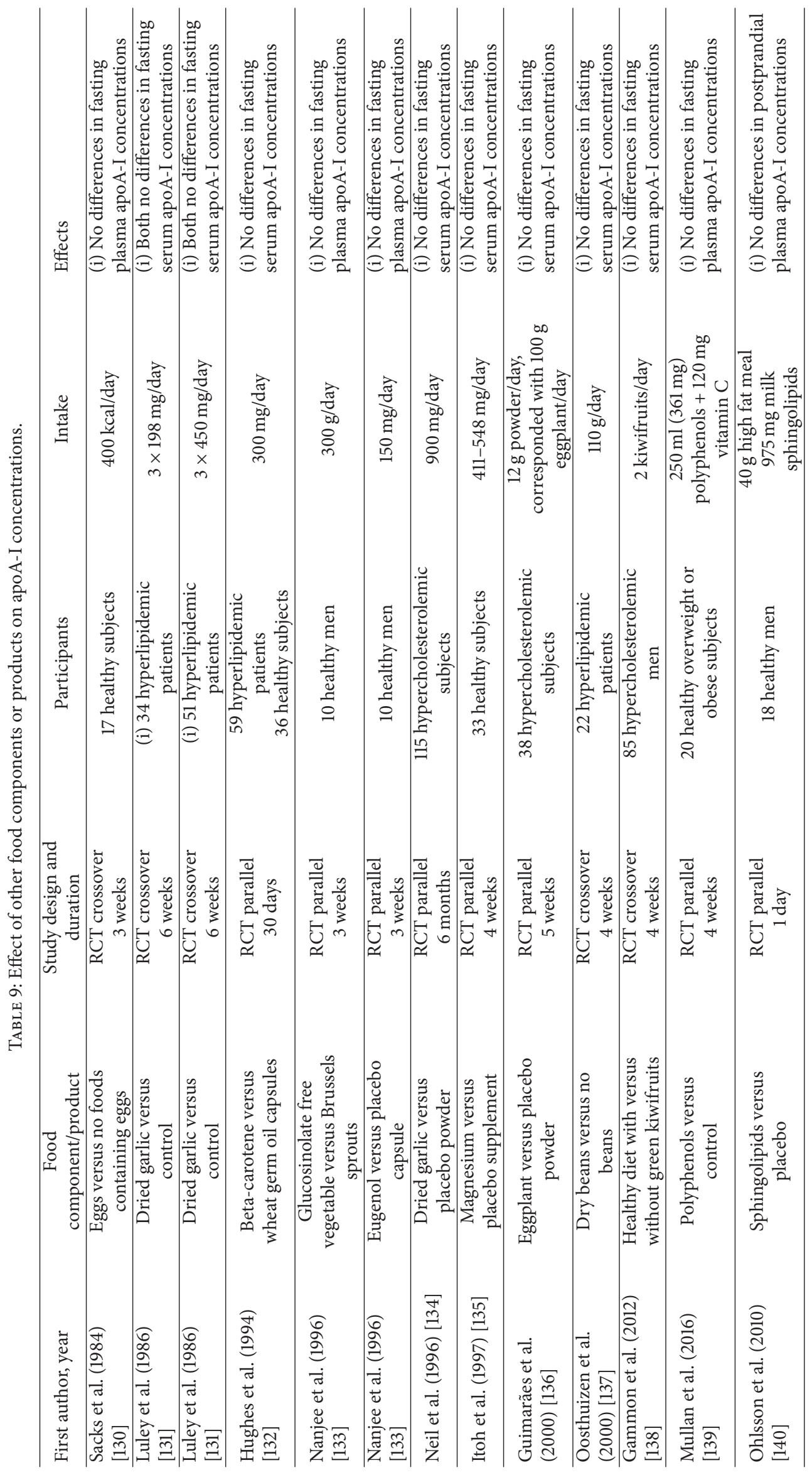




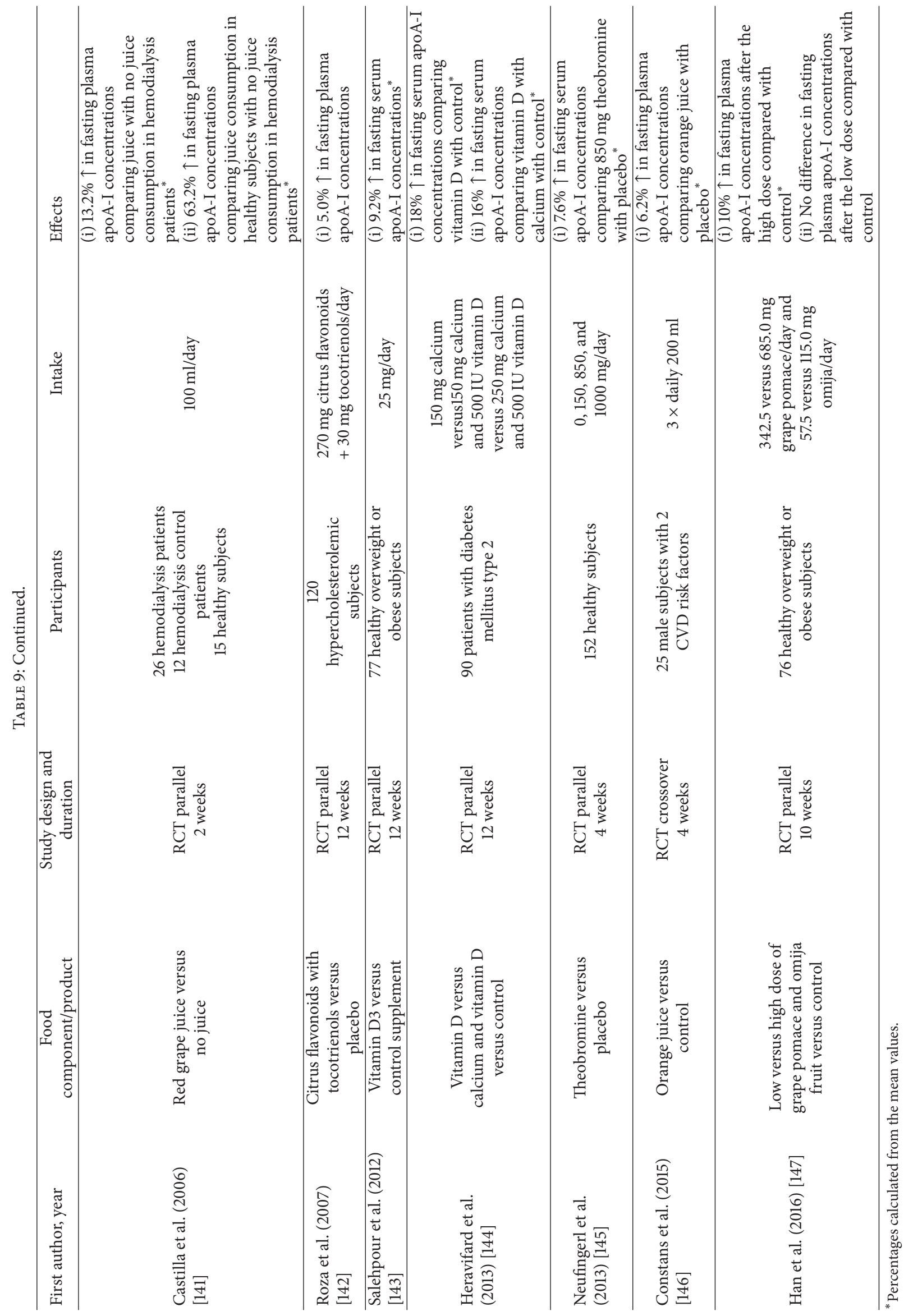


or can be infused $[15,173]$. To prevent digestion in the gastrointestinal tract, mimetics are made from $\mathrm{D}$-amino acids, which are resistant to human gastrointestinal proteolytic enzymes [14]. Over the years, several mimetics have been produced, but none of them has all the antiatherogenic functions of apoA-I. However, combining several mimetics can be a theoretical approach to mimic all antiatherosclerotic properties of apoA-I [174]. The only mimetic that has been tested in humans is $\mathrm{D}-4 \mathrm{~F}$. When 50 patients with coronary artery disease received a single oral dose $(30,100,300$, and $500 \mathrm{mg}$ ) of this mimetic, the two highest doses increased the anti-inflammatory activity of the HDL fraction. However, no changes in lipids or lipoprotein concentrations were seen. D$4 \mathrm{~F}$ was shown to be safe and well tolerated (Table 10) [148]. Unfortunately, the effects of D-4F on cholesterol efflux in humans have not yet been investigated.

4.2. ApoA-I Infusions. Besides apoA-I mimetics, apoA-I itself, either by using delipidated HDL or by using delipidated HDL combined with phospholipids, can be infused directly into the circulation. The theoretical advantage of using apoAI or apoA-I-phospholipid complexes instead of using apoA-I mimetics is that the apoA-I protein is completely intact and still possesses all its biological functions and might therefore have a larger atheroprotective effect. So far, three different forms of apoA-I have been tested, that is, apoA-I Milano (MDCO-216), CSL-111/CSL112, and CER-001.

4.2.1. ApoA-I Milano. In a randomized human controlled trial, 47 patients with acute coronary syndromes received for 5 weeks one infusion of placebo or recombinant apoA-I Milano/phospholipid complex (ETC-216) at 15 or $45 \mathrm{mg} / \mathrm{kg}$ per week. At the end of the study a significant reduction in atheroma volume was found in the high dose group [149]. This reduction in atheroma volume was accompanied by a reduction in external elastic membrane volume of the artery, but not with a change in lumen volume [175]. Recently, in a randomized controlled study, patients with stable coronary artery disease received 5 doses of $10,20,30$, and $40 \mathrm{mg} / \mathrm{kg}$ MDCO-216 infusion. This resulted in a dose-dependent increase in apoA-I concentrations and a dose-dependent shift from small- to large-sized HDL particles [150]. Moreover, a profound increase in ABCA1-mediated cholesterol efflux was observed [151]. However, very recently the MILANOPILOT study failed to slow down the regression of coronary atherosclerosis with 5 weekly infusions of $20 \mathrm{mg} / \mathrm{kg}$ MDCO216 in 120 patients with acute coronary syndromes. In fact, significant reductions in HDL-C and apoA-I concentrations were observed, while there were no effects found on percent atheroma volume and total atheroma volume (Table 10) [152].

4.2.2. CSL-111/CSL112. In one clinical study, 40 and $80 \mathrm{mg} / \mathrm{kg}$ CSL-111 were infused once a week for one month in 183 patients elected for coronary angiography. Treatment of the high dose group $(80 \mathrm{mg} / \mathrm{kg}$ ) was discontinued early, because some of the patients exceeded the upper level of alanine aminotransferase by 100 -fold. The low dose group ( $40 \mathrm{mg} / \mathrm{kg}$ ) showed a significant reduction in atheroma volume. However, this reduction was not significantly different from the decrease in the placebo group [176]. After this, the further development program of CSL-111 was discontinued because of the unfavorable hepatic abnormalities. As a follow-up, one phase I study has been performed using CSL112, which is a similar compound, but postulated without effects on liver function. In this study, a single dose $(5,15,40,70,105$, or $135 \mathrm{mg} / \mathrm{kg}$ ) or multiple doses for 4 weeks (3.4 or $6.7 \mathrm{~g}$ once a week or $3.4 \mathrm{~g}$ twice a week) of CSL112 was administrated intravenously to healthy volunteers. Both the single and multiple doses of CSL112 dose dependently increased serum apoA-I and serum HDL-C concentrations. Moreover, also pre- $\beta$ HDL particle concentrations and cholesterol efflux capacity were increased. In the single dose study, dosedependent effects were found on HDL-C $[153,154]$. Recently, two studies showed that CSL112 was indeed safe for human consumption, with no effects on liver function parameters $[155,156]$. In the first study, patients with atherosclerosis were given infusions of $1.7,3.4$, and $6.8 \mathrm{~g}$ CSL112 or placebo. The CSL112 infusions resulted in a dose-dependent increase in apoA-I and total cholesterol efflux [155]. In the second study patients with myocardial infarction received infusions of 2 or $6 \mathrm{~g}$ CSL112 or placebo for 4 weeks. Here also a dose-dependent increased in HDL-C, apoA-I, and cholesterol efflux was shown (Table 10) [156].

4.2.3. CER-001. In one clinical study, 417 patients with acute coronary syndromes were randomized for 6 weekly infusions of 3,6 , and $12 \mathrm{mg} / \mathrm{kg}$ CER-001 or placebo. No changes in atheroma volumes were found. It was speculated that a higher dose or a different patient group would have shown more positive results [157]. In a recent human study, 9 infusions of $8 \mathrm{mg} / \mathrm{kg}$ CER-001 were given twice weekly for 28 days to 7 patients with familial hypoalphalipoproteinemia, who were severely deficient in HDL. In this patient group, CER-001 significantly increased serum apoA-I and HDL$\mathrm{C}$ concentrations and reduced atherosclerotic lesion size, measured using Magnetic Resonance Imaging. Moreover, an increase in cholesterol efflux from macrophages and a higher fecal neutral sterol excretion was seen, which may indicate improved RCT [158]. Additionally, 12 biweekly infusions with $8 \mathrm{mg} / \mathrm{kg}$ CER-001 showed increased apoA-I concentrations, a decrease in vessel wall area, and a trend toward a reduction in vessel wall thickness [159]. Recently, a study evaluated the effects of $3 \mathrm{mg} / \mathrm{kg}$ CER-001, in patients with atherosclerotic carotid artery disease, and showed increased apoA-I concentrations, with a simultaneously increased cholesterol efflux capacity [160]. Unfortunately, preliminary data of a recent clinical trial in patients with coronary atherosclerosis did not show beneficial effects of CER-001 on atheroma volume and LDL-C [161] (Table 10).

\subsection{Others}

4.3.1. $R V X-208$. The first class of compounds affecting apoAI metabolism refers to the apoA-I transcriptional upregulator RVX-208. RVX-208 is an oral, small synthetic quinazoline molecule, which binds bromo- and extra terminal (BET) proteins and upregulates apoA-I gene transcription via an epigenetic mechanism. 


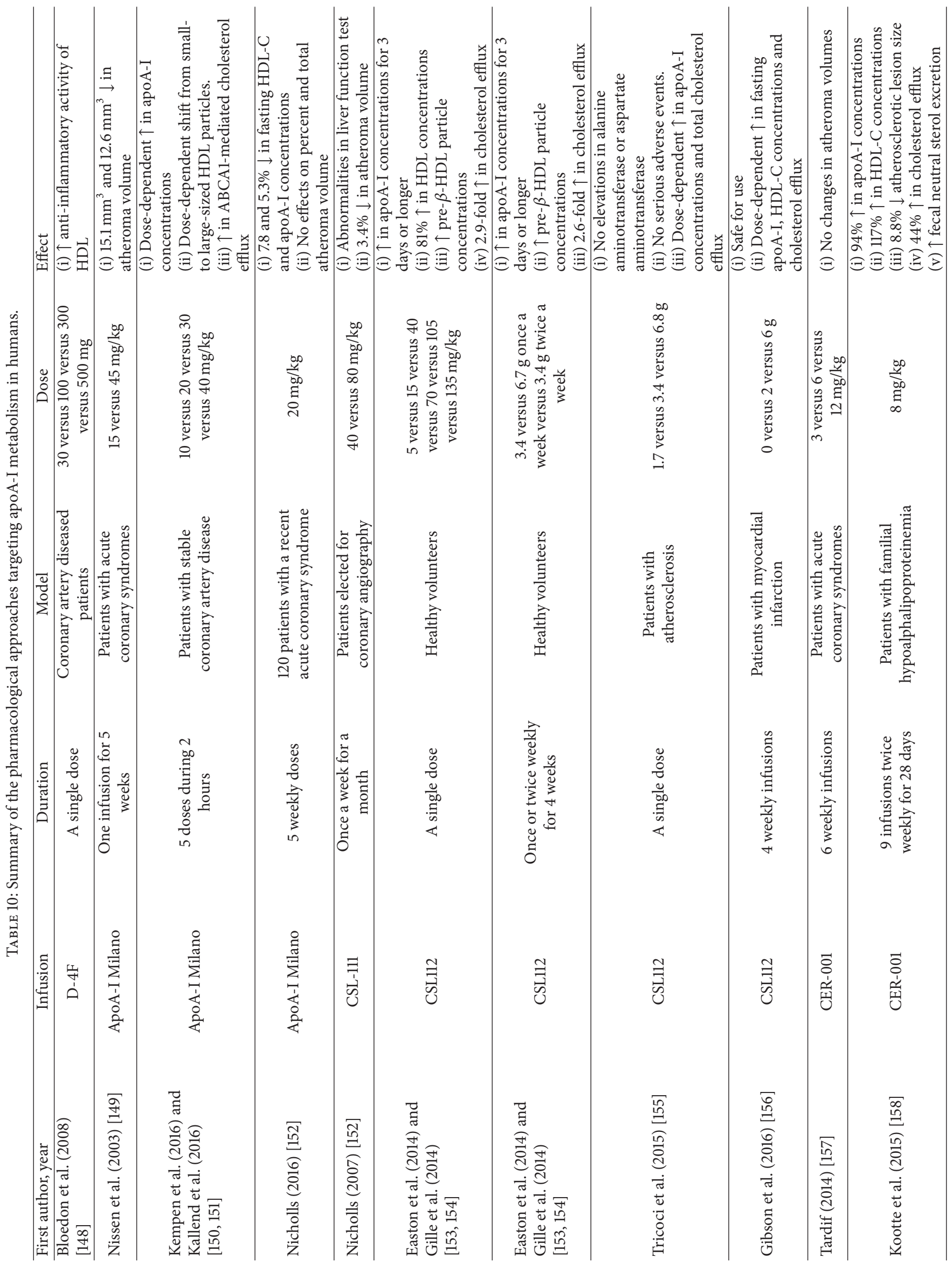




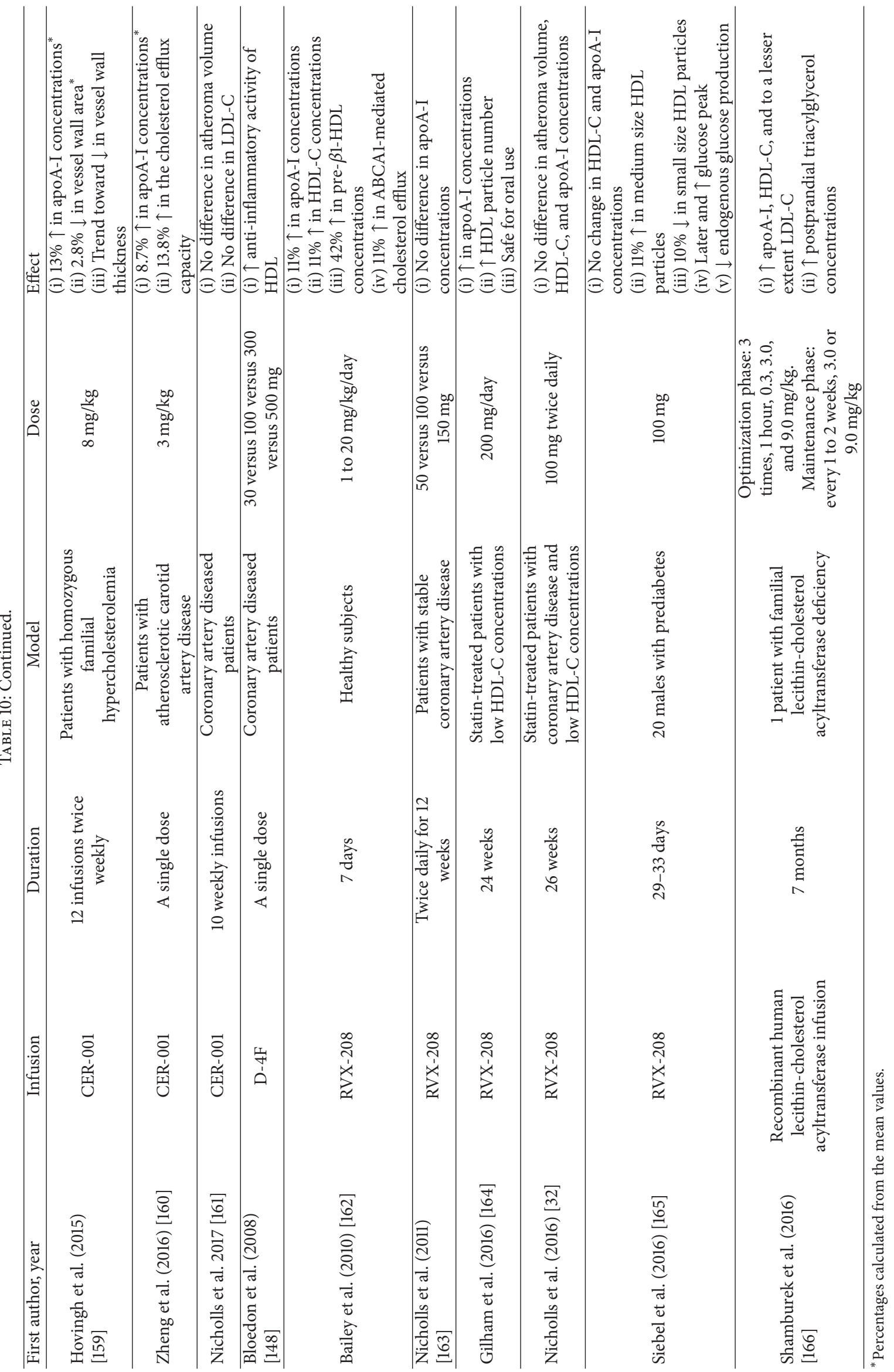


In the first human clinical trial, 18 healthy subjects received varying and multiple doses (1 to $20 \mathrm{mg} / \mathrm{kg}$ per day) of RVX-208 or placebo for 7 days. Plasma apoA-I concentrations were increased, and more importantly, an increase in pre- $\beta 1$-HDL concentrations and a higher ABCA1-mediated cholesterol efflux was demonstrated [162]. The outcome of the recent phase 2 randomized placebo-controlled clinical ASSERT trial, evaluating the effect of RVX-208 on serum apoA-I concentrations and CHD risk in human, was less positive. In that study, 299 patients with stable coronary artery disease received placebo or RVX-208 at three different dosages $(50,100$, and $150 \mathrm{mg}$ ) twice daily for 12 weeks. Only a nonsignificant increase in serum apoA-I concentrations was found. Unfortunately, HDL functionality and cholesterol efflux capacity were not studied [163]. A second study using RVX-208 is the phase $2 \mathrm{~b}$ clinical trial SUSTAIN. In this trial, 172 statin-treated patients (Rosuvastatin or Atorvastatin) with low serum HDL-C concentrations were treated with $200 \mathrm{mg} /$ day RVX-208 for 24 weeks. Both serum apoA-I concentrations and HDL particle numbers increased significantly. Furthermore, RVX-208 was found to be safe for oral use [164]. In another phase 2 clinical trial, the ASSURE study, 323 statin (Rosuvastatin or Atorvastatin) treated patients with coronary artery disease and low serum HDL-C concentrations received 100 mg RVX-208 twice daily for 26 weeks. However, no significant reductions in atheroma volume or increases in HDL-C and apoA-I concentrations were seen [32]. Finally, a recent study in subjects with prediabetes showed that $100 \mathrm{mg}$ RVX-208 for 29-33 days did not increase HDL-C and apoA-I concentrations, while it increased the concentration of medium-sized HDL and decreased the concentration of small-sized HDL particles. Furthermore, RVX-208 delayed and reduced oral glucose absorption and endogenous glucose production (Table 10) [165].

4.3.2. LCAT Infusion. The first human study investigating the effects of lecithin-cholesterol acyltransferase (LCAT) infusion investigated only one patient with familial LCAT deficiency. Recombinant human LCAT was infused 3 times for 1 hour in a dose optimization phase $(0.3,3.0$, and $9.0 \mathrm{mg} / \mathrm{kg}$ ) and after this 1 to 2 weekly infusions were given of 3.0 or $9.0 \mathrm{mg} / \mathrm{kg}$ for 7 months. LCAT infusion improved renal function, increased apoA-I, HDL-C, and to a lesser extent LDL-C. Furthermore, after infusion, postprandial triacylglycerol concentrations decreased [166]. These results are promising; however, before drawing conclusions about LCAT infusion clinical trials including more patients should be done.

\section{Conclusion}

Alcohol consumption increases fasting apoA-I concentrations and may improve cholesterol efflux, possibly via increasing apoA-I PR and decreasing FCR. Further, replacement of carbohydrates for SFA, cis-MUFA, cis-PUFA, and TFA increases fasting apoA-I concentrations. The effects of the various SFA are different, since lauric, palmitic, and myristic acids increase apoA-I concentrations, while stearic acid does not. The different fatty acids affect apoA-I metabolism differently, but results are conflicting. Therefore more studies are needed to better understand the effects of the various macronutrients on apoA-I kinetics.

Coffee, caffeine, tea, omega 3 fatty acid, fish, nuts, plant sterol and stanol, different soy proteins, and isoflavones isolated from soy do not change fasting apoA-I concentrations. Moreover, the effects of the various types of fibers may be different; the consumption of diets rich in wheat germ did not modify apoA-I concentrations, while the consumption of diets rich in psyllium, arabinoxylan, and flaxseed may decrease fasting apoA-I concentrations. However, these types of fibers have only been examined in a limited number of studies. Therefore, we conclude that fiber consumption does not have a profound impact on fasting apoA-I concentrations.

Finally, five other food components showed a promising increase in fasting apoA-I concentrations: citrus, vitamin $\mathrm{D}$, theobromine, orange juice, and a high dose of grape pomace and omija fruit. However, these findings need to be confirmed in future studies. Additional research is also needed to examine the effects of these products or food components not only on apoA-I kinetics, but also on HDL functionality.

Overall, all three categories of pharmacological approaches showed that targeting apoA-I concentrations and/or HDL functionality by a pharmacologic approach can increase apoA-I functionality and might improve CHD risk markers, including vessel wall characteristics and inflammation. The mimetic $\mathrm{D}-4 \mathrm{~F}$ is promising, but clinical studies are required to investigate the effects on HDL functionality. The CSL112 and LCAT infusions are the most promising of the infusion therapies, but studies are needed to investigate the effects of CSL112 on CHD risk markers, including vessel wall characteristics and inflammation, and LCAT infusions need to be investigated in clinical trials with more patients. Unfortunately, recent clinical studies showed no improvement in CHD risk markers after apoA-I Milano, RVX-208, or CER-001 therapy.

Although we cannot exclude that we have missed studies during the systematic searches and studies with positive results are overrepresented, we conclude that both dietary components and pharmacological approaches can be used to increase apoA-I concentrations. For the dietary components in particular, more knowledge about underlying mechanisms is necessary, as increasing apoA-I per se does not necessarily translate into a reduced CHD risk.

\section{Conflicts of Interest}

The authors have no conflicts of interest.

\section{Acknowledgments}

This research was supported by the Dutch Technology Foundation (STW), which is part of the Netherlands Organisation for Scientific Research (NWO) and which is partly funded by the Ministry of Economic Affairs. 


\section{References}

[1] S. J. Nicholls, A. D. Pisaniello, Y. Kataoka, and R. Puri, "Lipid pharmacotherapy for treatment of atherosclerosis," Expert Opinion on Pharmacotherapy, vol. 15, no. 8, pp. 1119-1125, 2014.

[2] B. G. Nordestgaard, M. J. Chapman, S. E. Humphries et al., "Familial hypercholesterolaemia is underdiagnosed and undertreated in the general population: guidance for clinicians to prevent coronary heart disease: consensus statement of the european atherosclerosis society," European Heart Journal, vol. 34, article 15, 2013.

[3] R. Gadi and V. M. Figueredo, "Low-density lipoprotein cholesterol lowering therapies: what is on the horizon?" Journal of Cardiovascular Medicine, vol. 16, no. 1, pp. 1-10, 2015.

[4] K. Dalton, "Conference News, AHA 2014. Ezetimibe Proves Clinical Benefit on Top of Statin Therapy," Conference News, AHA 2014 https://www.tctmd.com/news/ezetimibe-provesclinical-benefit-top-statin-therapy.

[5] S. P. J. Dullens, J. Plat, and R. P. Mensink, "Increasing apoAI production as a target for CHD risk reduction," Nutrition, Metabolism and Cardiovascular Diseases, vol. 17, no. 8, pp. 616628, 2007.

[6] M. Miller, P. Langenberg, and S. Havas, "Impact of lowering triglycerides on raising HDL-C in hypertriglyceridemic and non-hypertriglyceridemic subjects," International Journal of Cardiology, vol. 119, no. 2, pp. 192-195, 2007.

[7] R. Gadi, A. Amanullah, and V. M. Figueredo, "HDL-C: Does it matter? An update on novel HDL-directed pharmacotherapeutic strategies," International Journal of Cardiology, vol. 167, no. 3, pp. 646-655, 2013.

[8] C. E. Kosmas, G. Christodoulidis, J.-W. Cheng, T. J. Vittorio, and S. Lerakis, "High-density lipoprotein functionality in coronary artery disease," The American Journal of the Medical Sciences, vol. 347, no. 6, pp. 504-508, 2014.

[9] G. Luc, J.-M. Bard, J. Ferrières et al., "Value of HDL cholesterol, apolipoprotein A-I, lipoprotein A-I, and lipoprotein A-I/A-II in prediction of coronary heart disease: the PRIME study," Arteriosclerosis, Thrombosis, and Vascular Biology, vol. 22, no. 7, pp. 1155-1161, 2002.

[10] G. Franceschini, L. Calabresi, G. Chiesa et al., "Increased cholesterol efflux potential of sera from ApoA-I(Milano) carriers and transgenic mice," Arteriosclerosis, Thrombosis, and Vascular Biology, vol. 19, no. 5, pp. 1257-1262, 1999.

[11] J. W. Anderson, L. D. Allgood, A. Lawrence et al., "Cholesterollowering effects of psyllium intake adjunctive to diet therapy in men and women with hypercholesterolemia: meta-analysis of 8 controlled trials," American Journal of Clinical Nutrition, vol. 71, pp. $472-479,2000$.

[12] C. J. Fielding and P. E. Fielding, "Molecular physiology of reverse cholesterol transport," The Journal of Lipid Research, vol. 36, pp. 211-228, 1995.

[13] L. P. Smits, R. S. Kootte, and E. S. Stroes, "Reversal of atherosclerosis with apolipoprotein A1: back to basics," Atherosclerosis, vol. 232, no. 1, pp. 217-219, 2014.

[14] T. L. Eggerman, J. M. Hoeg, M. S. Meng, A. Tombragel, D. Bojanovski, and H. B. Brewer Jr., "Differential tissue-specific expression of human apoA-I and apoA-II," Journal of Lipid Research, vol. 32, pp. 821-828, 1991.

[15] M. Navab, G. M. Anantharamaiah, S. Hama et al., "Oral administration of an apo A-I mimetic peptide synthesized from $\mathrm{D}$-amino acids dramatically reduces atherosclerosis in mice independent of plasma cholesterol," Circulation, vol. 105, no. 3, pp. 290-292, 2002.

[16] A. M. Scanu and C. Edelstein, "HDL: bridging past and present with a look at the future," FASEB Journal, vol. 22, no. 12, pp. 4044-4054, 2008.

[17] D. Sviridov, L. E. Pyle, M. Jauhiainen, C. Ehnholm, and N. H. Fidge, "Deletion of the propeptide of apolipoprotein AI reduces protein expression but stimulates effective conversion of prebeta-high density lipoprotein to alpha-high density lipoprotein," Journal of Lipid Research, vol. 41, pp. 1872-1882, 2000.

[18] P. Chau, P. E. Fielding, and C. J. Fielding, "Bone morphogenetic protein-1 (BMP-1) cleaves human proapolipoprotein A1 and regulates its activation for lipid binding," Biochemistry, vol. 46, no. 28, pp. 8445-8450, 2007.

[19] F. Oldoni, R. J. Sinke, and J. A. Kuivenhoven, "Mendelian disorders of high-density lipoprotein metabolism," Circulation Research, vol. 114, no. 1, pp. 124-142, 2014.

[20] X. L. Zheng, S. Matsubara, C. Diao, M. D. Hollenberg, and N. C. Wong, "Epidermal growth factor induction of apolipoprotein A-I is mediated by the Ras-MAP kinase cascade and Spl," Journal of Biological Chemistry, vol. 276, pp. 13822-13829, 2001.

[21] J. K. Lam, S. Matsubara, K. Mihara, X.-L. Zheng, A. D. Mooradian, and N. C. W. Wong, "Insulin induction of apolipoprotein AI, role of SP1," Biochemistry, vol. 42, no. 9, pp. 2680-2690, 2003.

[22] S. K. Moestrup, I. Schousboe, C. Jacobsen, J.-R. Leheste, E. I. Christensen, and T. E. Willnow, " $\beta 2$-glycoprotein-I (apolipoprotein $\mathrm{H}$ ) and $\beta 2$-glycoprotein-I- phospholipid complex harbor a recognition site for the endocytic receptor megalin," Journal of Clinical Investigation, vol. 102, no. 5, pp. 902-909, 1998.

[23] X. Zhang, J. J. Jiao, B. R. Bhavnani, and S. P. Tam, "Regulation of human apolipoprotein A-I gene expression by equine estrogens," Journal Lipid Research, vol. 42, pp. 1789-1800, 2001.

[24] K. Nagao, M. Hata, K. Tanaka et al., "The roles of C-terminal helices of human apolipoprotein A-I in formation of highdensity lipoprotein particles," Biochimica et Biophysica Acta, vol. 1841, no. 1, pp. 80-87, 2014.

[25] G. V. Upton, "Lipids, cardiovascular disease, and oral contraceptives: a practical perspective," Fertility and Sterility, vol. 53, no. 1, pp. 1-12, 1990.

[26] C. K. Glass, R. C. Pittman, G. A. Keller, and D. Steinberg, "Tissue sites of degradation of apoprotein A-I in the rat," Biological Chemistry, vol. 258, pp. 7161-7167, 1983.

[27] J. A. Krikken, R. T. Gansevoort, and R. P. F. Dullaart, "Lower HDL-C and apolipoprotein A-I are related to higher glomerular filtration rate in subjects without kidney disease," Journal of Lipid Research, vol. 51, no. 7, pp. 1982-1990, 2010.

[28] S. K. Moestrup and L. B. Nielsen, "The role of the kidney in lipid metabolism," Current Opinion in Lipidology, vol. 16, no. 3, pp. 301-306, 2005.

[29] R. Kozyraki, J. Fyfe, M. Kristiansen et al., "The intrinsic factorvitamin B12 receptor, cubilin, is a high-affinity apolipoprotein A-I receptor facilitating endocytosis of high-density lipoprotein," Nature Medicin, vol. 5, pp. 656-661, 1999.

[30] E. I. Christensen, H. Birn, P. Verroust, and S. K. Moestrup, "Megalin-mediated endocytosis in renal proximal tubule," Renal Failure, vol. 20, no. 2, pp. 191-199, 1998.

[31] S. K. Moestrup, R. Kozyraki, M. Kristiansen et al., "The intrinsic factor-vitamin B12 receptor and target of teratogenic antibodies is a megalin-binding peripheral membrane protein 
with homology to developmental proteins," Journal of Biological Chemistry, vol. 273, no. 9, pp. 5235-5242, 1998.

[32] S. J. Nicholls, R. Puri, K. Wolski et al., "Effect of the bet protein inhibitor, RVX-208, on progression of coronary atherosclerosis: results of the phase $2 b$, randomized, double-blind, multicenter, ASSURE trial," American Journal of Cardiovascular Drugs, vol. 16, no. 1, pp. 55-65, 2016.

[33] S. E. Brien, P. E. Ronksley, B. J. Turner, K. J. Mukamal, and W. A. Ghali, "Effect of alcohol consumption on biological markers associated with risk of coronary heart disease: systematic review and meta-analysis of interventional studies," British Medical Journal, vol. 342, article d636, 2011.

[34] G. Chiva-Blanch, M. Urpi-Sarda, E. Ros et al., "Effects of red wine polyphenols and alcohol on glucose metabolism and the lipid profile: a randomized clinical trial," Clinical Nutrition, vol. 32, no. 2, pp. 200-206, 2013.

[35] M. S. van der Gaag, A. van Tol, L. M. Scheek et al., "Daily moderate alcohol consumption increases serum paraoxonase activity; a diet-controlled, randomised intervention study in middle-aged men," Atherosclerosis, vol. 147, no. 2, pp. 405-410, 1999.

[36] M. S. van der Gaag, A. van Tol, S. H. Vermunt, L. M. Scheek, G. Schaafsma, and H. F. Hendriks, "Alcohol consumption stimulates early steps in reverse cholesterol transport," Journal ofLipid Research, pp. 42-2077, 2001.

[37] A. Lavy, B. Fuhrman, A. Markel et al., "Effect of dietary supplementation of red or white wine on human blood chemistry, hematology and coagulation: favorable effect of red wine on plasma high-density lipoprotein," Annals of Nutrition and Metabolism, vol. 38, no. 5, pp. 287-294, 1994.

[38] Y. Gepner, R. Golan, I. Harman-Boehm et al., "Effects of initiating moderate alcohol intake on cardiometabolic risk in adults with type 2 diabetes: a 2-year randomized, controlled trial," Annals of Internal Medicine, vol. 163, no. 8, pp. 569-579, 2015.

[39] J. W. J. Beulens, A. Sierksma, A. Van Tol et al., "Moderate alcohol consumption increases cholesterol efflux mediated by ABCA1," Journal of Lipid Research, vol. 45, no. 9, pp. 1716-1723, 2004.

[40] I. Kralova Lesna, P. Suchanek, P. Stavek, and R. Poledne, "May alcohol-induced increase of HDL be considered as atheroprotective?” Physiology Research, vol. 59, pp. 407-413, 2010.

[41] F. Gottrand, L. Beghin, N. Duhal et al., "Moderate red wine consumption in healthy volunteers reduced plasma clearance of apolipoprotein AII," European Journal of Clinical Investigation, vol. 29, no. 5, pp. 387-394, 1999.

[42] A. Aro, J. Teirilä, and C.-G. Gref, "Dose-dependent effect on serum cholesterol and apoprotein B concentrations by consumption of boiled, non-filtered coffee," Atherosclerosis, vol. 83, no. 2-3, pp. 257-261, 1990.

[43] A. Aro, J. Tuomilehto, E. Kostiainen, U. Uusitalo, and P. Pietinen, "Bioled coffee increases serum low density lipoprotein concentration," Metabolism, vol. 36, no. 11, pp. 1027-1030, 1987.

[44] M. L. Burr, J. E. Gallacher, B. K. Butland, C. H. Bolton, and L. G. Downs, "Coffee, blood pressure and plasma lipids: a randomized controlled trial," Eur J Clinical Nutrition, vol. 43, pp. 477-483, 1989.

[45] M. J. Davies, J. T. Judd, D. J. Baer et al., "Black tea consumption reduces total and LDL cholesterol in mildly hypercholesterolemic adults," Journal of Nutrition, vol. 133, pp. 3298S-3302S, 2003.

[46] H. Mozaffari-Khosravi, B.-A. Jalali-Khanabadi, M. AfkhamiArdekani, and F. Fatehi, "Effects of sour tea (Hibiscus sabdariffa) on lipid profile and lipoproteins in patients with type II diabetes," Journal of Alternative and Complementary Medicine, vol. 15, no. 8, pp. 899-903, 2009.

[47] M. van Dusseldorp, M. B. Katan, T. van Vliet, P. N. Demacker, and A. F. Stalenhoef, "Cholesterol-raising factor from boiled coffee does not pass a paper filter," Arteriosclerosis Thrombosis and Vascular Biology, vol. 11, pp. 586-593, 1991.

[48] R. Mensink, Effects of Saturated Fatty Acids on Serum Lipids and Lipoproteins: A Systematic Review and Regression Analysis, World Health Organization, Geneva, 2016.

[49] I. Brouwer, Effect of Trans-Fatty Acid Intake on Blood Lipids and Lipoproteins: A Systematic Review and Meta-Regression Analysis, World Health Organization, Geneva, 2016.

[50] H. N. Ginsberg, W. Karmally, S. L. Barr, C. Johnson, S. Holleran, and R. Ramakrishnan, "Effects of increasing dietary polyunsaturated fatty acids within the guidelines of the AHA step 1 diet on plasma lipid and lipoprotein levels in normal males," Arteriosclerosis, Thrombosis, and Vascular Biology, vol. 14, no. 6, pp. 892-901, 1994.

[51] S. Desroches, M.-E. Paradis, M. Pérusse et al., "Apolipoprotein A-I, A-II, and VLDL-B-100 metabolism in men: comparison of a low-fat diet and a high-monounsaturated fatty acid diet," Journal of Lipid Research, vol. 45, no. 12, pp. 2331-2338, 2004.

[52] N. R. Matthan, F. K. Welty, P. H. R. Barrett et al., "Dietary hydrogenated fat increases high-density lipoprotein apoA-I catabolism and decreases low-density lipoprotein apoB-100 catabolism in hypercholesterolemic women," Arteriosclerosis, Thrombosis, and Vascular Biology, vol. 24, no. 6, pp. 1092-1097, 2004.

[53] M.-È. Labonté, D. J. A. Jenkins, G. F. Lewis et al., “Adding MUFA to a dietary portfolio of cholesterol-lowering foods reduces apoAI fractional catabolic rate in subjects with dyslipidaemia," British Journal of Nutrition, vol. 110, no. 3, pp. 426-436, 2013.

[54] G. Schectman, S. Kaul, and A. H. Kissebah, "Effect of fish oil concentrate on lipoprotein composition in NIDDM," Diabetes, vol. 37, no. 11, pp. 1567-1573, 1988.

[55] T. J. Wilt, R. P. Lofgren, K. L. Nichol et al., "Fish oil supplementation does not lower plasma cholesterol in men with hypercholesterolemia. Results of a randomized, placebo-controlled crossover study," Annals of Internal Medicine, vol. 111, no. 11, pp. 900-905, 1989.

[56] M. T. Childs, I. B. King, and R. H. Knopp, "Divergent lipoprotein responses to fish oils with various ratios of eicosapentaenoic acid and docosahexaenoic acid," American Journal of Clinical Nutrition, vol. 52, pp. 632-639, 1990.

[57] J. P. DeLany, V. M. Vivian, J. T. Snook, and P. A. Anderson, "Effects of fish oil on serum lipids in men during a controlled feeding trial," American Journal of Clinical Nutrition, vol. 52, pp. 477-485, 1990.

[58] P. D. Levinson, A. H. losiphidis, A. L. Saritelli, P. N. Herbert, and M. Steiner, "Effects of n-3 fatty acids in essential hypertension," American Journal of Hypertension, vol. 3, no. 10, pp. 754-760, 1990.

[59] T. A. Mori, R. Vandongen, and J. R. L. Masarei, "Fish oilInduced changes in apolipoproteins in IDDM subjects," Diabetes Care, vol. 13, no. 7, pp. 725-732, 1990.

[60] K. H. Boønaa, K. S. Bjerve, and A. Nordoøy, "Docosahexaenoic and eicosapentaenoic acids in plasma phospholipids are divergently associated with high density lipoprotein in humans," Arteriosclerosis, Thrombosis, and Vascular Biology, vol. 12, no. 6, pp. 675-681, 1992. 
[61] W. O. Richter, B. G. Jacob, M. M. Ritter, and P. Schwandt, "Treatment of primary chylomicronemia due to familial hypertriglyceridemia by $\omega-3$ fatty acids," Metabolism, vol. 41, no. 10, pp. 1100-1105, 1992.

[62] F. Tatò, C. Keller, and G. Wolfram, "Effects of fish oil concentrate on lipoproteins and apolipoproteins in familial combined hyperlipidemia," The Clinical Investigator, vol. 71, no. 4, pp. 314318, 1993.

[63] A. Zampelas, A. S. Peel, B. J. Gould, J. Wright, and C. M. Williams, "Polyunsaturated fatty acids of the n- 6 and n-3 series: effects on postprandial lipid and apolipoprotein levels in healthy men," European Journal of Clinical Nutrition, vol. 48, pp. 842848,1994

[64] J. Eritsland, H. Arnesen, I. Seljeflot, and A. T. Hostmark, "Longterm metabolic effects of n-3 polyunsaturated fatty acids in patients with coronary artery disease," American Journal of Clinical Nutrition, vol. 61, pp. 831-836, 1995.

[65] W. Herrmann, J. Biermann, and G. M. Kostner, "Comparison of effects of N-3 to N-6 fatty acids on serum level of lipoprotein(a) in patients with coronary artery disease," The American Journal of Cardiology, vol. 76, no. 7, pp. 459-462, 1995.

[66] T. Hamazaki, S. Sawazaki, E. Asaoka et al., "Docosahexaenoic acid-rich fish oil does not affect serum lipid concentrations of normolipidemic young adults," Journal of Nutrition, vol. 126, pp. 2784-2789, 1996.

[67] S. Grimsgaard, K. H. Bonaa, J. B. Hansen, and A. Nordoy, "Highly purified eicosapentaenoic acid and docosahexaenoic acid in humans have similar triacylglycerol-lowering effects but divergent effects on serum fatty acids," American Journal of Clinical Nutrition, vol. 66, pp. 649-659, 1997.

[68] N. S. Sorensen, P. Marckmann, C. E. Hoy, W. van Duyvenvoorde, and H. M. Princen, "Effect of fish-oil-enriched margarine on plasma lipids, low-density-lipoprotein particle composition, size, and susceptibility to oxidation," American Journal of Clinical Nutrition, vol. 68, pp. 235-241, 1998.

[69] R. Buckley, B. Shewring, R. Turner, P. Yaqoob, and A. M. Minihane, "Circulating triacylglycerol and apoE levels in response to EPA and docosahexaenoic acid supplementation in adult human subjets," British Journal of Nutrition, vol. 92, no. 3, pp. 477-483, 2004.

[70] L. Calabresi, B. Villa, M. Canavesi et al., "An $\omega-3$ polyunsaturated fatty acid concentrate increases plasma high-density lipoprotein 2 cholesterol and paraoxonase levels in patients with familial combined hyperlipidemia," Metabolism, vol. 53, no. 2, pp. 153-158, 2004.

[71] F. Shidfar, A. Keshavarz, S. Hosseyni, A. Ameri, and S. Yarahmadi, "Effects of omega-3 fatty acid supplements on serum lipids, apolipoproteins and malondialdehyde in type 2 diabetes patients," Eastern Mediterranean Health Journal, vol. 14, pp. 305-313, 2008.

[72] Z. Li, S. Lamon-Fava, J. Otvos et al., "Fish consumption shifts lipoprotein subfractions to a less atherogenic pattern in humans," Journal of Nutrition, vol. 134, pp. 1724-1728, 2004.

[73] P. L. L. Goyens and R. P. Mensink, "Effects of alpha-linolenic acid versus those of EPA/DHA on cardiovascular risk markers in healthy elderly subjects," European Journal of Clinical Nutrition, vol. 60, no. 8, pp. 978-984, 2006.

[74] B. De Roos, A. Geelen, K. Ross et al., "Identification of potential serum biomarkers of inflammation and lipid modulation that are altered by fish oil supplementation in healthy volunteers," Journal of Proteomics, vol. 8, no. 10, pp. 1965-1974, 2008.
[75] F. Shidfar, A. Keshavarz, M. Jallali, R. Miri, and M. Eshraghian, "Comparison of the effects of simultaneous administration of vitamin $\mathrm{C}$ and omega-3 fatty acids on lipoproteins, apo AI, apo B, and malondialdehyde in hyperlipidemic patients," International Journal for Vitamin and Nutrition Research, vol. 73, no. 3, pp. 163-170, 2003.

[76] K. C. Maki, A. L. Lawless, K. M. Kelley et al., "Effects of prescription omega-3-acid ethyl esters on fasting lipid profile in subjects with primary hypercholesterolemia," Journal of Cardiovascular Pharmacology, vol. 57, no. 4, pp. 489-494, 2011.

[77] E. M. M. Ooi, A. H. Lichtenstein, J. S. Millar et al., "Effects of therapeutic lifestyle change diets high and low in dietary fish-derived FAs on lipoprotein metabolism in middle-aged and elderly subjects," Journal of Lipid Research, vol. 53, no. 9, pp. 1958-1967, 2012.

[78] Z. Song, L. Yang, G. Shu, H. Lu, and G. Sun, "Effects of the $n-6 / n-3$ polyunsaturated fatty acids ratio on postprandial metabolism in hypertriacylglycerolemia patients," Lipids in Health and Disease, vol. 12, no. 1, article 181, 2013.

[79] J. M. Oliveira, P. H. Rondo, J. S. Yudkin et al., "Effects of fish oil on lipid profile and other metabolic outcomes in HIV-infected patients on antiretroviral therapy: a randomized placebo-controlled trial," International Journal of STD \& AIDS, vol. 25, pp. 96-104, 2014.

[80] F. M. Stewart, J. M. Neutze, and R. Newsome-White, “The addition of oatbran to a low fat diet has no effect on lipid values in hypercholesterolaemic subjects," New Zealand Medical Journal, vol. 105, no. 14, pp. 398-400, 1992.

[81] A. Gascon, H. Jacques, S. Moorjani, Y. Deshaies, L.-D. Brun, and P. Julien, "Plasma lipoprotein profile and lipolytic activities in response to the substitution of lean white fish for other animal protein sources in premenopausal women," American Journal of Clinical Nutrition, vol. 63, pp. 315-321, 1996.

[82] H. Lindqvist, A. M. Langkilde, I. Undeland, T. Rådendal, and A. S. Sandberg, "Herring (Clupea harengus) supplemented diet influences risk factors for CVD in overweight subjects," European Journal of Clinical Nutrition, vol. 61, no. 9, pp. 11061113, 2007.

[83] A. T. Erkkilä, U. S. Schwab, V. D. F. De Mello et al., "Effects of fatty and lean fish intake on blood pressure in subjects with coronary heart disease using multiple medications," European Journal of Nutrition, vol. 47, no. 6, pp. 319-328, 2008.

[84] C. Isherwood, M. Wong, W. S. Jones, I. G. Davies, and B. A. Griffin, "Lack of effect of cold water prawns on plasma cholesterol and lipoproteins in normo-lipidaemic men," Cellular and Molecular Biology, vol. 56, pp. 52-58, 2010.

[85] J. W. Anderson, N. H. Gilinsky, D. A. Deakins et al., "Lipid Responses of hypercholesterolemic men to oat-bran and wheatbran intake," American Journal of Clinical Nutrition, vol. 54, pp. 678-683, 1991.

[86] L. Cara, C. Dubois, P. Borel et al., "Effects of oat bran, rice bran, wheat fiber, and wheat germ on postprandial lipemia in healthy adults," American Journal of Clinical Nutrition, vol. 55, pp. 81-88, 1992.

[87] H. Kashtan, H. S. Stern, D. Jenkins et al., "Wheat-bran and oat-bran supplements' effects on blood lipids and lipoproteins," American Journal of Clinical Nutrition, vol. 55, pp. 976-980, 1992.

[88] M. I. Uusitupa, E. Ruuskanen, E. Makinen et al., "A controlled study on the effect of beta-glucan-rich oat bran on serum lipids in hypercholesterolemic subjects: relation to apolipoprotein $\mathrm{E}$ 
phenotype," The Journal of the American College of Nutrition, vol. 11, pp. 651-659, 1992.

[89] J. X. Zhang, G. Hallmans, H. Andersson et al., "Effect of oat bran on plasma cholesterol and bile acid excretion in nine subjects with ileostomies," American Journal of Clinical Nutrition, vol. 56, pp. 99-105, 1992.

[90] N. Mekki, C. Dubois, M. Charbonnier et al., "Effects of lowering fat and increasing dietary fiber on fasting and postprandial plasma lipids in hypercholesterolemic subjects consuming a mixed Mediterranean-Western diet," American Journal of Clinical Nutrition, vol. 66, pp. 1443-1451, 1997.

[91] D. J. Jenkins, C. W. Kendall, C. J. Jackson et al., "Soluble fiber intake at a dose approved by the US Food and Drug Administration for a claim of health benefits: serum lipid risk factors for cardiovascular disease assessed in a randomized controlled crossover trial," American Journal of Clinical Nutrition, vol. 75, pp. 834-839, 2002.

[92] A. L. Garcia, J. Steiniger, S. C. Reich et al., "Arabinoxylan fibre consumption improved glucose metabolism, but did not affect serum adipokines in subjects with impaired glucose tolerance," Hormone and Metabolic Research, vol. 38, no. 11, pp. 761-766, 2006.

[93] R. Sola, G. Godas, J. Ribalta et al., "Effects of soluble fiber (Plantago ovata husk) on plasma lipids, lipoproteins, and apolipoproteins in men with ischemic heart disease," American Journal of Clinical Nutrition, vol. 85, pp. 1157-1163, 2007.

[94] M. Rondanelli, A. Opizzi, F. Monteferrario, C. Klersy, R. Cazzola, and B. Cestaro, "Beta-glucan- or rice bran-enriched foods: a comparative crossover clinical trial on lipidic pattern in mildly hypercholesterolemic men," European Journal of Clinical Nutrition, vol. 65, no. 7, pp. 864-871, 2011.

[95] S. Dodin, S. C. Cunnane, B. Mâsse et al., "Flaxseed on cardiovascular disease markers in healthy menopausal women: a randomized, double-blind, placebo-controlled trial," Nutrition, vol. 24, no. 1, pp. 23-30, 2008.

[96] R. van Houwelingen, H. Zevenbergen, P. Groot, A. Kester, and G. Hornstra, "Dietary-fish effects on serum lipids and apolipoproteins, a controlled study," American Journal of Clinical Nutrition, vol. 51, pp. 393-398, 1990.

[97] K. N. Aronis, M. T. Vamvini, J. P. Chamberland et al., "Short-term walnut consumption increases circulating total adiponectin and apolipoprotein A concentrations, but does not affect markers of inflammation or vascular injury in obese humans with the metabolic syndrome: data from a doubleblinded, randomized, placebo-controlled study," Metabolism, vol. 61, no. 4, pp. 577-582, 2012.

[98] S. Munoz, M. Merlos, D. Zambon et al., "Walnut-enriched diet increases the association of LDL from hypercholesterolemic men with human HepG2 cells," Journal of Lipid Research, vol. 42, pp. 2069-2076, 2001.

[99] S. Rajaram, E. H. Haddad, A. Mejia, and J. Sabaté, "Walnuts and fatty fish influence different serum lipid fractions in normal to mildly hyperlipidemic individuals: A randomized controlled study," American Journal of Clinical Nutrition, vol. 89, no. 5, pp. 1657S-1663S, 2009.

[100] S.-C. Li, Y.-H. Liu, J.-F. Liu, W.-H. Chang, C.-M. Chen, and C.Y. O. Chen, "Almond consumption improved glycemic control and lipid profiles in patients with type 2 diabetes mellitus," Metabolism, vol. 60, no. 4, pp. 474-479, 2011.

[101] J. Sabaté, E. Haddad, J. S. Tanzman, P. Jambazian, and S. Rajaram, "Serum Lipid Response to the graduated enrichment of a Step I diet with almonds: a randomized feeding trial,"
American Journal of Clinical Nutrition, vol. 77, pp. 1379-1384, 2003.

[102] S. M. Mercanligil, P. Arslan, C. Alasalvar et al., "Effects of hazelnut-enriched diet on plasma cholesterol and lipoprotein profiles in hypercholesterolemic adult men," European Journal of Clinical Nutrition, vol. 61, no. 2, pp. 212-220, 2007.

[103] S. L. Tey, R. C. Brown, A. W. Chisholm, C. M. Delahunty, A. R. Gray, and S. M. Williams, "Effects of different forms of hazelnuts on blood lipids and $\alpha$-tocopherol concentrations in mildly hypercholesterolemic individuals," European Journal of Clinical Nutrition, vol. 65, no. 1, pp. 117-124, 2011.

[104] M. J. Sheridan, J. N. Cooper, M. Erario, and C. E. Cheifetz, "Pistachio nut consumption and serum lipid levels," Journal of the American College of Nutrition, vol. 26, no. 2, pp. 141-148, 2007.

[105] H. Gylling and T. A. Miettinen, "Serum cholesterol and cholesterol and lipoprotein metabolism in hypercholesterolaemic NIDDM patients before and during sitostanol ester- margarine treatment," Diabetologia, vol. 37, no. 8, pp. 773-780, 1994.

[106] E. H. M. Temme, P. G. A. van Hoydonck, E. G. Schouten, and H. Kesteloot, "Effects of a plant sterol-enriched spread on serum lipids and lipoproteins in mildly hypercholesterolaemic subjects," Acta Cardiologica, vol. 57, no. 2, pp. 111-115, 2002.

[107] A. L. Amundsen, L. Ose, M. S. Nenseter, and F. Y. Ntanios, "Plant sterol ester-enriched spread lowers plasma total and LDL cholesterol in children with familial hypercholesterolemia," American Journal of Clinical Nutrition, vol. 76, pp. 338-344, 2002.

[108] Y.-M. Chan, I. Demonty, D. Pelled, and P. J. H. Jones, “Olive oil containing olive oil fatty acid esters of plant sterols and dietary diacylglycerol reduces low-density lipoprotein cholesterol and decreases the tendency for peroxidation in hypercholesterolaemic subjects," British Journal of Nutrition, vol. 98, no. 3, pp. 563-570, 2007.

[109] M. B. Madsen, A.-M. Jensen, and E. B. Schmidt, "The effect of a combination of plant sterol-enriched foods in mildly hypercholesterolemic subjects," The American Journal of Clinical Nutrition, vol. 26, no. 6, pp. 792-798, 2007.

[110] E. M. Ooi, G. F. Watts, P. H. Barrett et al., "Dietary plant sterols supplementation does not alter lipoprotein kinetics in men with the metabolic syndrome," Asia and Pacific Journal of Clinical Nutrition, vol. 16, pp. 624-631, 2007.

[111] A. Hernández-Mijares, C. Bañuls, M. Rocha et al., "Effects of phytosterol ester-enriched low-fat milk on serum lipoprotein profile in mildly hypercholesterolaemic patients are not related to dietary cholesterol or saturated fat intake," British Journal of Nutrition, vol. 104, no. 7, pp. 1018-1025, 2010.

[112] P. P. Söderholm, G. Alfthan, A. H. Koskela, H. Adlercreutz, and M. J. Tikkanen, "The effect of high-fiber rye bread enriched with nonesterified plant sterols on major serum lipids and apolipoproteins in normocholesterolemic individuals," Nutrition, Metabolism and Cardiovascular Diseases, vol. 22, no. 7, pp. 575-582, 2012.

[113] A. C. M. Gagliardi, R. C. Maranho, H. P. D. Sousa, E. J. Schaefer, and R. D. Santos, "Effects of margarines and butter consumption on lipid profiles, inflammation markers and lipid transfer to HDL particles in free-living subjects with the metabolic syndrome," European Journal of Clinical Nutrition, vol. 64, no. 10, pp. 1141-1149, 2010.

[114] T. E. Sialvera, G. D. Pounis, A. E. Koutelidakis et al., "Phytosterols supplementation decreases plasma small and dense LDL levels in metabolic syndrome patients on a westernized type 
diet," Nutrition, Metabolism and Cardiovascular Diseases, vol. 22, no. 10, pp. 843-848, 2012.

[115] R. M. Bakhit, B. P. Klein, D. Essex-Sorlie, J. O. Ham, J. W. Erdman, and S. M. Potter, "Potter SM. Intake of $25 \mathrm{~g}$ of soybean protein with or without soybean fiber alters plasma lipids in men with elevated cholesterol concentrations," Journal of Nutrition, vol. 124, pp. 213-222, 1994.

[116] E. M. Kurowska, J. Jordan, J. D. Spence et al., "Effects of substituting dietary soybean protein and oil for milk protein and fat in subjects with hypercholesterolemia," Clinical Investment Medicine, vol. 20, pp. 162-170, 1997.

[117] K. Nilausen and H. Meinertz, "Variable lipemic response to dietary soy protein in healthy, normolipemic men," American Journal of Clinical Nutrition, vol. 68, pp. 1380S-1384S, 1998.

[118] D. J. A. Jenkins, C. W. C. Kendall, E. Vidgen et al., "Effect of soybased breakfast cereal on blood lipids and oxidized low-density lipoprotein," Metabolism, vol. 49, no. 11, pp. 1496-1500, 2000.

[119] S.-T. Chen, J.-R. Chen, C.-S. Yang, S.-J. Peng, and S.-H. Feng, "Effect of soya protein on serum lipid profile and lipoprotein concentrations in patients undergoing hypercholesterolaemic haemodialysis," British Journal of Nutrition, vol. 95, no. 2, pp. 366-371, 2006.

[120] B. L. McVeigh, B. L. Dillingham, J. W. Lampe, and A. M. Duncan, "Effect of soy protein varying in isoflavone content on serum lipids in healthy young men," American Journal of Clinical Nutrition, vol. 83, pp. 244-251, 2006.

[121] E. A. Pipe, C. P. Gobert, S. E. Capes, G. A. Darlington, J. W. Lampe, and A. M. Duncan, "Soy protein reduces serum LDL cholesterol and the LDL cholesterol:HDL cholesterol and apolipoprotein B:apolipoprotein A-I ratios in adults with type 2 diabetes," Journal of Nutrition, vol. 139, no. 9, pp. 1700-1706, 2009.

[122] S. C. Campbell, D. A. Khalil, M. E. Payton, and B. H. Arjmandi, "One-year soy protein supplementation does not improve lipid profile in postmenopausal women," Menopause, vol. 17, no. 3, pp. 587-593, 2010.

[123] H. Tabibi, H. Imani, M. Hedayati, S. Atabak, and L. Rahmani, "Effects of soy consumption on serum lipids and apoproteins in peritoneal dialysis patients: a randomized controlled trial," Peritoneal Dialysis International, vol. 30, no. 6, pp. 611-618, 2010.

[124] D. J. Jenkins, C. W. Kendall, C. J. Jackson et al., "Effects of highand low-isoflavone soyfoods on blood lipids, oxidized LDL, homocysteine, and blood pressure in hyperlipidemic men and women," American Journal of Clinical Nutrition, vol. 76, pp. 365372, 2002.

[125] A. F. G. Cicero, A. Fiorito, M. P. Panourgia, Z. Sangiorgi, and A. Gaddi, "Effects of a new soy/ $\beta$-sitosterol supplement on plasma lipids in moderately hypercholesterolemic subjects," Journal of the American Dietetic Association, vol. 102, no. 12, pp. 1807-1811, 2002.

[126] N. R. Matthan, S. M. Jalbert, L. M. Ausman, J. T. Kuvin, R. H. Karas, and A. H. Lichtenstein, "Effect of soy protein from differently processed products on cardiovascular disease risk factors and vascular endothelial function in hypercholesterolemic subjects," American Journal of Clinical Nutrition, vol. 85, pp. 960-966, 2007.

[127] A. Bakhtiary, Z. Yassin, P. Hanachi, A. Rahmat, Z. Ahmad, and F. Jalali, "Effects of soy on metabolic biomarkers of cardiovascular disease in elderly women with metabolic syndrome," Archives of Iranian Medicine, vol. 15, pp. 462-468, 2012.

[128] K. E. Wangen, A. M. Duncan, X. Xu, and M. S. Kurzer, "Soy isoflavones improve plasma lipids in normocholesterolemic and mildly hypercholesterolemic postmenopausal women," American Journal of Clinical Nutrition, vol. 73, pp. 225-231, 2001.

[129] A. S. Santo, A. M. Santo, R. W. Browne et al., "Postprandial lipemia detects the effect of soy protein on cardiovascular disease risk compared with the fasting lipid profile," Lipids, vol. 45, no. 12, pp. 1127-1138, 2010.

[130] F. Sacks, L. Miller, M. Sutherland et al., "Ingestion of egg raises plasma low density lipoproteins in free-living subjects," The Lancet, vol. 323, no. 8378, pp. 647-649, 1984.

[131] C. Luley, W. Lehmann-Leo, B. Moller, T. Martin, and W. Schwartzkopff, "Lack of efficacy of dried garlic in patients with hyperlipoproteinemia," Arzneimittelforschung, vol. 36, pp. 766$768,1986$.

[132] G. S. Hughes, T. V. Ringer, S. F. Francom, L. K. Means, and M. J. DeLoof, "Lack of effects of beta-carotene on lipids and sex steroid hormones in hyperlipidemics," American Journal of Medical Science, vol. 308, pp. 16-22, 1994.

[133] M. N. Nanjee, H. Verhagen, G. van Poppel, C. J. Rompelberg, P. J. van Bladeren, and N. E. Miller, "Do dietary phytochemicals with cytochrome P-450 enzyme-inducing activity increase high-density-lipoprotein concentrations in humans?" American Journal of Clinical Nutrition, vol. 64, pp. 706-711, 1996.

[134] H. A. Neil, C. A. Silagy, T. Lancaster et al., "Garlic powder in the treatment of moderate hyperlipidaemia: a controlled trial and meta-analysis," The Journal of the Royal College of Physicians, vol. 30, pp. 329-334, 1996.

[135] K. Itoh, T. Kawasaki, and M. Nakamura, "The effects of high oral magnesium supplementation on blood pressure, serum lipids and related variables in apparently healthy Japanese subjects," British Journal of Nutrition, vol. 78, no. 5, pp. 737-750, 1997.

[136] P. R. Guimarães, A. M. P. Galvão, C. M. Batista et al., "Eggplant (Solanum melongena) infusion has a modest and transitory effect on hypercholesterolemic subjects," Brazilian Journal of Medical and Biological Research, vol. 33, no. 9, pp. 1027-1036, 2000.

[137] W. Oosthuizen, C. S. Scholtz, H. H. Vorster, J. C. Jerling, and W. J. H. Vermaak, "Extruded dry beans and serum lipoprotein and plasma haemostatic factors in hyperlipidaemic men," European Journal of Clinical Nutrition, vol. 54, no. 5, pp. 373-379, 2000.

[138] C. S. Gammon, R. Kruger, A. M. Minihane, C. A. Conlon, P. R. Von Hurst, and W. Stonehouse, "Kiwifruit consumption favourably affects plasma lipids in a randomised controlled trial in hypercholesterolaemic men," British Journal of Nutrition, vol. 109, no. 12, pp. 2208-2218, 2013.

[139] A. Mullan, C. Delles, W. Ferrell et al., "Effects of a beverage rich in (poly)phenols on established and novel risk markers for vascular disease in medically uncomplicated overweight or obese subjects: a four week randomized trial," Atherosclerosis, vol. 246, pp. 169-176, 2016.

[140] L. Ohlsson, H. Burling, R.-D. Duan, and A. Nilsson, "Effects of a sphingolipid-enriched dairy formulation on postprandial lipid concentrations," European Journal of Clinical Nutrition, vol. 64, no. 11, pp. 1344-1349, 2010.

[141] P. Castilla, R. Echarri, A. Davalos et al., "Concentrated red grape juice exerts antioxidant, hypolipidemic, and antiinflammatory effects in both hemodialysis patients and healthy subjects," American Journal of Clinical Nutrition, vol. 84, pp. 252-262, 2006.

[142] J. M. Roza, Z. Xian-Liu, and N. Guthrie, "Effect of citrus flavonoids and tocotrienols on serum cholesterol levels in 
hypercholesterolemic subjects," Alternative Therapy in Health Medicine, vol. 13, pp. 44-48, 2007.

[143] A. Salehpour, F. Shidfar, F. Hosseinpanah et al., "Vitamin D3 and the risk of CVD in overweight and obese women: a randomised controlled trial," British Journal of Nutrition, vol. 108, no. 10, pp. 1866-1873, 2012.

[144] S. Heravifard, T. R. Neyestani, B. Nikooyeh et al., "Regular consumption of both vitamin D- and calcium- and vitamin Dfortified yogurt drink is equally accompanied by lowered blood lipoprotein (a) and elevated apoprotein A1 in subjects with type 2 diabetes: a randomized clinical trial," Journal of the American College of Nutrition, vol. 32, no. 1, pp. 26-30, 2013.

[145] N. Neufingerl, Y. E. M. P. Zebregs, E. A. H. Schuring, and E. A. Trautwein, "Effect of cocoa and theobromine consumption on serum HDL-cholesterol concentrations: a randomized controlled trial," American Journal of Clinical Nutrition, vol. 97, no. 6, pp. 1201-1209, 2013.

[146] J. Constans, C. Bennetau-Pelissero, J.-F. Martin et al., "Marked antioxidant effect of orange juice intake and its phytomicronutrients in a preliminary randomized cross-over trial on mild hypercholesterolemic men," Clinical Nutrition, vol. 34, no. 6, pp. 1093-1100, 2015.

[147] H. J. Han, U. J. Jung, H.-J. Kim et al., "Combined supplementation with grape pomace and omija fruit ethanol extracts dosedependently improves body composition, plasma lipid profiles, inflammatory status, and antioxidant capacity in overweight and obese subjects," Journal of Medicinal Food, vol. 19, no. 2, pp. 170-180, 2016.

[148] L. T. Bloedon, R. Dunbar, D. Duffy et al., "Safety, pharmacokinetics, and pharmacodynamics of oral apoA-I mimetic peptide $\mathrm{D}-4 \mathrm{~F}$ in high-risk cardiovascular patients," Journal of Lipid Research, vol. 49, no. 6, pp. 1344-1352, 2008.

[149] S. E. Nissen, T. Tsunoda, E. M. Tuzcu et al., "Effect of recombinant ApoA-I milano on coronary atherosclerosis in patients with acute coronary syndromes: a randomized controlled trial," Journal of the American Medical Association, vol. 290, no. 17, pp. 2292-2300, 2003.

[150] H. J. Kempen, B. F. Asztalos, M. Moerland et al., "High-density lipoprotein subfractions and cholesterol efflux capacities after infusion of MDCO-216 (apolipoprotein A-IMilano/PalmitoylOleoyl-Phosphatidylcholine) in healthy volunteers and stable coronary artery disease patients," Arteriosclerosis, Thrombosis, and Vascular Biology, vol. 36, no. 4, pp. 736-742, 2016.

[151] D. G. Kallend, J. A. Reijers, S. E. Bellibas et al., "A single infusion of MDCO-216 (ApoA-1 Milano/POPC) increases ABCA1mediated cholesterol efflux and pre-beta $1 \mathrm{HDL}$ in healthy volunteers and patients with stable coronary artery disease," European Heart Journal of Cardiovascular pharmacotherapy, vol. 2, pp. 23-29, 2016.

[152] S. Nicholls, "Impact of Infusion of an ApoA-I Milano $_{\text {HDL }}$ Mimetic on Regression of Coronary Atherosclerosis in Acute Coronary Syndrome patients: the MILANO-PILOT Study," 2016 http://www.abstractsonline.com/pp8/\#!/4096/presentation $/ 58822$.

[153] R. Easton, A. Gille, D. D’Andrea, R. Davis, S. D. Wright, and C. Shear, "A multiple ascending dose study of CSL112, an infused formulation of ApoA-I," Journal of Clinical Pharmacology, vol. 54, no. 3, pp. 301-310, 2014.

[154] A. Gille, R. Easton, D. D’Andrea, S. D. Wright, and C. L. Shear, "CSL112 enhances biomarkers of reverse cholesterol transport after single and multiple infusions in healthy subjects," Arteriosclerosis, Thrombosis, and Vascular Biology, vol. 34, no. 9, pp. 2106-2114, 2014.

[155] P. Tricoci, D. M. D’Andrea, P. A. Gurbel et al., "Infusion of reconstituted high-density lipoprotein, CSL112, in patients with atherosclerosis: safety and pharmacokinetic results from a phase 2a randomized clinical trial," Journal of the American Heart Association, vol. 4, Article ID e002171, 2015.

[156] C. M. Gibson, S. Korjian, P. Tricoci et al., "Rationale and design of Apo-I Event Reduction in Ischemic Syndromes I (AEGIS-I): a phase $2 \mathrm{~b}$, randomized, placebo-controlled, dose-ranging trial to investigate the safety and tolerability of CSL112, a reconstituted, infusible, human apoA-I, after acute myocardial infarction," American Heart Journal, vol. 180, pp. 22-28, 2016.

[157] J. C. Tardif, C. M. Ballantyne, P. Barter et al., "Effects of the high-density lipoprotein mimetic agent CER-001 on coronary atherosclerosis in patients with acute coronary syndromes: a randomized trial," European Heart Journal, vol. 29, article 29, 2014.

[158] R. Kootte, L. Smits, F. van der Valk et al., "Effect of open-label infusion of an apolipoprotein A-I-containing particle (CER001) on reverse cholesterol transport and artery wall thickness in patients with familial hypo-alphalipoproteinemia," Journal of lipid research, vol. 235, article e14, no. 2, 2014.

[159] G. K. Hovingh, L. P. Smits, C. Stefanutti et al., "The effect of an apolipoprotein A-I-containing high-density lipoproteinmimetic particle (CER-001) on carotid artery wall thickness in patients with homozygous familial hypercholesterolemia: the Modifying Orphan Disease Evaluation (MODE) study," American Heart Journal, vol. 169, no. 5, pp. 736-742, 2015.

[160] K. H. Zheng, F. M. van der Valk, L. P. Smits et al., "HDL mimetic CER-001 targets atherosclerotic plaques in patients," Atherosclerosis, vol. 251, pp. 381-388, 2016.

[161] S. Nicholls, "CARAT: Novel HDL Mimetic fails to Show Benefit in Coronary Atherosclerosis after ACS," 2017 https://www .tctmd.com/news/carat-novel-hdl-mimetic-fails-show-benefitcoronary-atherosclerosis-after-acs.

[162] D. Bailey, R. Jahagirdar, A. Gordon et al., "RVX-208. A small molecule that increases apolipoprotein a-i and high-density lipoprotein cholesterol in vitro and in vivo," Journal of the American College of Cardiology, vol. 55, no. 23, pp. 2580-2589, 2010.

[163] S. J. Nicholls, A. Gordon, J. Johansson et al., "Efficacy and safety of a novel oral inducer of apolipoprotein A-I synthesis in statin-treated patients with stable coronary artery disease: a randomized controlled trial," Journal of the American College of Cardiology, vol. 57, no. 9, pp. 1111-1119, 2011.

[164] D. Gilham, S. Wasiak, L. M. Tsujikawa et al., "Corrigendum to "RVX-208, a BET-inhibitor for treating atherosclerotic cardiovascular disease, raises ApoA-I/HDL and represses pathways that contribute to cardiovascular disease"," Atherosclerosis, vol. 247, pp. 48-57, 2016.

[165] A. L. Siebel, S. K. Trinh, M. F. Formosa et al., "Effects of the BET-inhibitor, RVX-208 on the HDL lipidome and glucose metabolism in individuals with prediabetes: a randomized controlled trial," Metabolism, vol. 65, no. 6, pp. 904-914, 2016.

[166] R. D. Shamburek, R. Bakker-Arkema, B. J. Auerbach et al., "Familial lecithin:cholesterol acyltransferase deficiency: firstin-human treatment with enzyme replacement," Journal of Clinical Lipidology, vol. 10, no. 2, pp. 356-367, 2016.

[167] E. J. Schaefer, S. Lamon-Fava, J. M. Ordovas et al., "Factors associated with low and elevated plasma high density lipoprotein 
cholesterol and apolipoprotein A-I levels in the Framingham Offspring Study," Journal of Lipid Research, vol. 35, pp. 871-882, 1994.

[168] P. J. Barter, M. Caulfield, M. Eriksson et al., "Effects of torcetrapib in patients at high risk for coronary events," The New England Journal of Medicine, vol. 357, no. 21, pp. 2109-2122, 2007.

[169] A. M. Gotto, C. P. Cannon, X. S. Li et al., "Evaluation of lipids, drug concentration, and safety parameters following cessation of treatment with the cholesteryl ester transfer protein inhibitor anacetrapib in patients with or at high risk for coronary heart disease," American Journal of Cardiology, vol. 113, no. 1, pp. 7683, 2014.

[170] S. J. Nicholls, H. B. Brewer, J. J. P. Kastelein et al., "Effects of the CETP inhibitor evacetrapib administered as monotherapy or in combination with statins on HDL and LDL cholesterol: a randomized controlled trial," JAMA-Journal of the American Medical Association, vol. 306, no. 19, pp. 2099-2109, 2011.

[171] G. G. Schwartz, A. G. Olsson, M. Abt et al., "Effects of dalcetrapib in patients with a recent acute coronary syndrome," The New England Journal of Medicine, vol. 367, no. 22, pp. 20892099, 2012.

[172] M. Navab, G. M. Anantharamaiah, S. T. Reddy et al., "Apolipoprotein A-I mimetic peptides-ATVB in focus," Arteriosclerosis, Thrombosis, and Vascular Biology, vol. 25, no. 7, pp. 1325-1331, 2005.

[173] E. M. Degoma and D. J. Rader, "Novel HDL-directed pharmacotherapeutic strategies," Nature Reviews Cardiology, vol. 8, no. 5, pp. 266-277, 2011.

[174] W. D’Souza, J. A. Stonik, A. Murphy et al., "Structure/function relationships of apolipoprotein A-I mimetic peptides: implications for antiatherogenic activities of high-density lipoprotein," Circulation Research, vol. 107, no. 2, pp. 217-227, 2010.

[175] S. J. Nicholls, E. M. Tuzcu, I. Sipahi et al., "Relationship between atheroma regression and change in lumen size after infusion of apolipoprotein A-I Milano," Journal of the American College of Cardiology, vol. 47, no. 5, pp. 992-997, 2006.

[176] J.-C. Tardif, J. Grégoire, P. L. L’Allier et al., "Effects of reconstituted high-density lipoprotein infusions on coronary atherosclerosis: a randomized controlled trial," Journal of the American Medical Association, vol. 297, no. 15, pp. 1675-1682, 2007. 


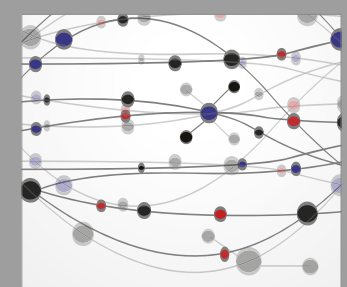

The Scientific World Journal
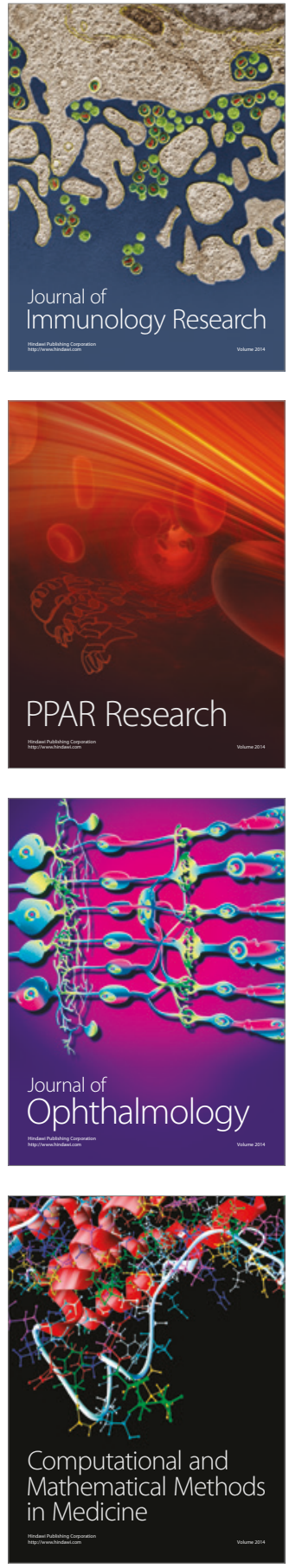

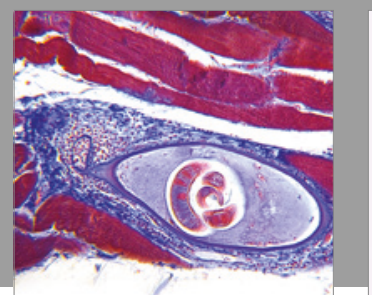

Gastroenterology Research and Practice
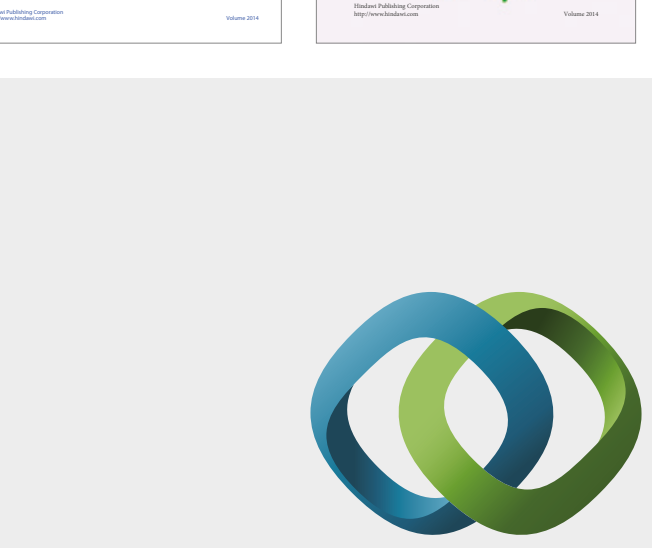

\section{Hindawi}

Submit your manuscripts at

https://www.hindawi.com
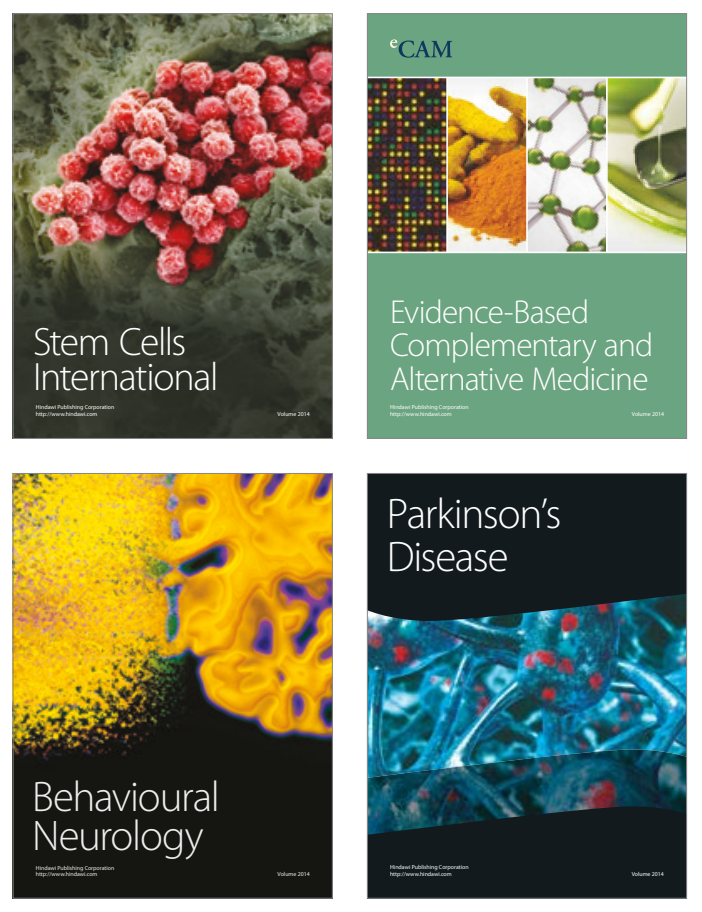
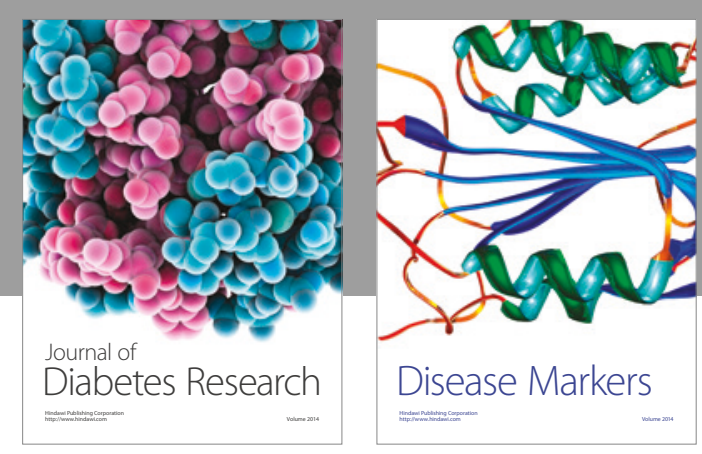

Disease Markers
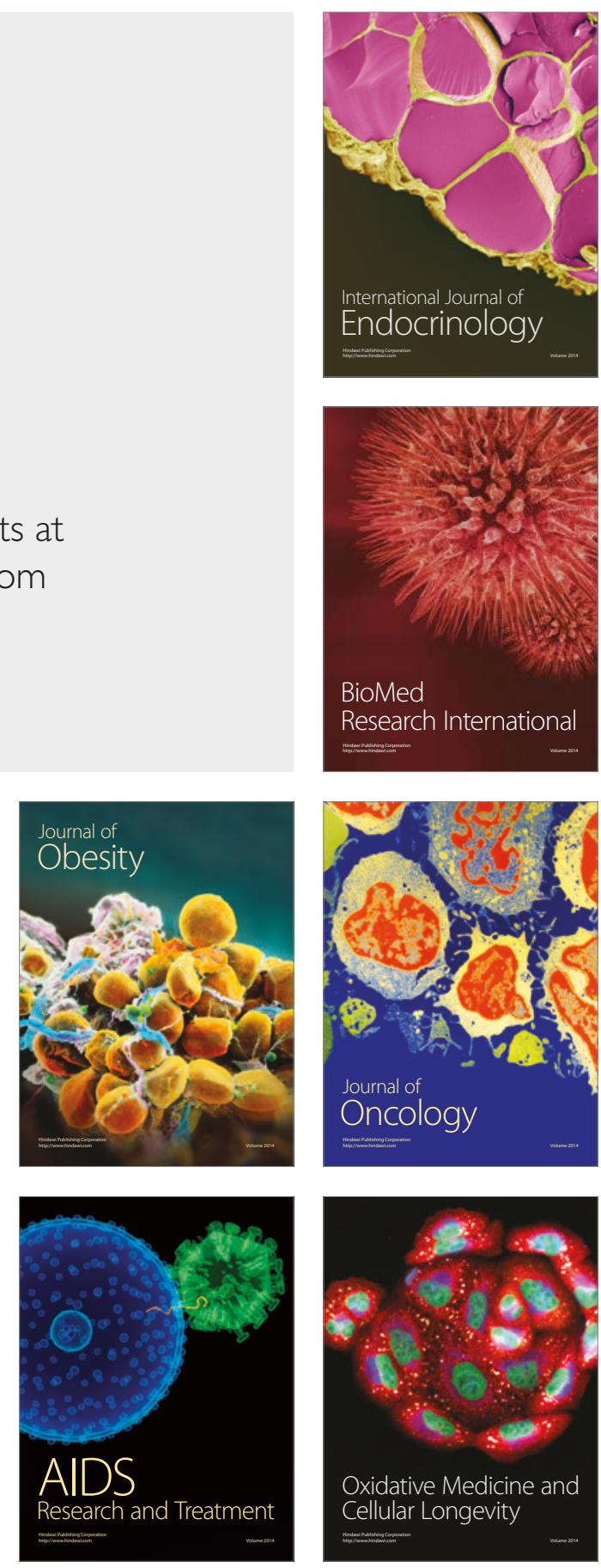